\title{
Exciting perspectives for Translational Myology in the Abstracts of the 2018Spring PaduaMuscleDays: Giovanni Salviati Memorial - Chapter II - Abstracts of March 15, 2018
}

Ugo Carraro $(1,2,3)$

(1) Laboratory of Translational Myology, Department of Biomedical Sciences, University of Padova; (2) A\&C M-C Foundation for Translational Myology, Padova; (3) IRCCS Fondazione Ospedale San Camillo, Venezia-Lido, Italy

This article is distributed under the terms of the Creative Commons Attribution Noncommercial License (CC BY-NC 4.0) which permits any noncommercial use, distribution, and reproduction in any medium, provided the original author(s) and source are credited.

\begin{abstract}
Myologists working in Padua (Italy) were able to continue a half-century tradition of studies of skeletal muscles, that started with a research on fever, specifically if and how skeletal muscle contribute to it by burning bacterial toxin. Beside main publications in high-impact-factor journals by Padua myologists, I hope to convince readers (and myself) of the relevance of the editing Basic and Applied Myology (BAM), retitled from 2010 European Journal of Translational Myology (EJTM), of the institution of the Interdepartmental Research Center of Myology of the University of Padova (CIR-Myo), and of a long series of International Conferences organized in Euganei Hills and Padova, that is, the PaduaMuscleDays. The 2018Spring PaduaMuscleDays (2018SpPMD), were held in Euganei Hills and Padua (Italy), in March 14-17, and were dedicated to Giovanni Salviati. The main event of the "Giovanni Salviati Memorial", was held in the Aula Guariento, Accademia Galileiana di Scienze, Lettere ed Arti of Padua to honor a beloved friend and excellent scientist 20 years after his premature passing. Using the words of Prof. Nicola Rizzuto, we all share his believe that Giovanni "will be remembered not only for his talent and originality as a biochemist, but also for his unassuming and humanistic personality, a rare quality in highly successful people like Giovanni. The best way to remember such a person is to gather pupils and colleagues, who shared with him the same scientific interests and ask them to discuss recent advances in their own fields, just as Giovanni have liked to do". Since Giovanni's friends sent many abstracts still influenced by their previous collaboration with him, all the Sessions of the 2018SpPMD reflect both to the research aims of Giovanni Salviati and the traditional topics of the PaduaMuscleDays, that is, basics and applications of physical, molecular and cellular strategies to maintain or recover functions of skeletal muscles. The translational researches summarized in the 2018SpPMD Abstracts are at the appropriate high level to attract approval of Ethical Committees, the interest of International Granting Agencies and approval for publication in top quality, international journals. In this chapter II are listed the abstracts of the March 15, 2018 Padua Muscle Day. All 2018SpPMD Abstracts are indexed at the end of the Chapter IV.
\end{abstract}

Key Words: Giovanni Salviati, proof of concept, translational myology, PaduaMuscleDays Eur J Transl Myol 28 (1): 10-29, 2018 


\section{Abstracts of the 2018-Spring Padua Muscle Day, March 15, 2018}

\section{Oxidative stress theory of aging still alive. Role of metals?}

\section{Christiaan Leeuwenburgh}

University of Florida, Institute on Aging, Department of Aging and Geriatric Research, Division of Biology of Aging, Gainesville, Florida, USA

\section{E-mail: cleeuwen@ufl.edu}

Key Words: Oxidative stress, aging, role of metals

It is still unknown what the exact source and cause is of DNA mutations and deletions in vivo. Oxidative stress, in general, has been thought to be the major culprit, but what the original source of the culprit is, is still unknown. Iron dyshomeostasis (high cellular and low systemic levels) are strong risk factors in the development of disease, disability and premature death Systemic iron deficiency (anemia with old age) impairs oxygen carrying capacity, while in contrast increased cellular and mitochondrial levels may increase DNA lesions. Disturbances of iron metabolism including uptake, export, and storage have shown to play a causal role in cellular and mitochondrial dysfunctions with age and disease. Iron is found in several forms: heme iron (i.e., haemoglobin, myoglobin) and non-heme iron (i.e., Ferritin). A distinct fraction of chelatable non-heme iron is referred to as the labile iron pool, which comprises less than $5 \%$ of total cellular iron (Figure 1). Labile iron consists of $\mathrm{Fe} 2+$ and $\mathrm{Fe} 3+$ ions associated with a variety of small molecules, including organic anions, polypeptides, and phospholipids. Labile iron can participate in Fenton reactions, producing highly destructive hydroxyl radicals, which are thought to be a major contributor to the formation of DNA mutatons and deletions. Cellular iron acquisition occurs through iron import proteins such as transferrin receptor (TfR1), divalent metal transporter-1 (DMT1), and Zip14, whereas cellular iron export is mediated by ferroportin (FPN), the only known iron exporter in mammals. The mitochondria contain mitoferrin (Mt iron importer), iron storage proteins such as frataxin, Mt ferritin (MtF) (which binds with iron), and ABCB7 (a heme export protein), all known to play an important role in the storage and regulation of Mt iron. We and others have found that in animals and humans, labile iron and nonheme iron increases with age and is associated with elevated expression of ferritin. In contrast, transferrin receptor 1 (TfR1; cellular iron import protein) showed a dramatic down regulation with age. We also find that mitochondrial iron levels effect Mt permeability transition pore opening susceptibility (i.e., $\mathrm{Ca} 2+$ retention capacity), mutations and deletions with age. We will present new data obtained from humans which show an association between iron deregulation and genome instability. ${ }^{1-5}$

1. Aydemir TB, Troche C, Kim J, et al. Aging amplifies multiple phenotypic defects in mice with zinc transporter

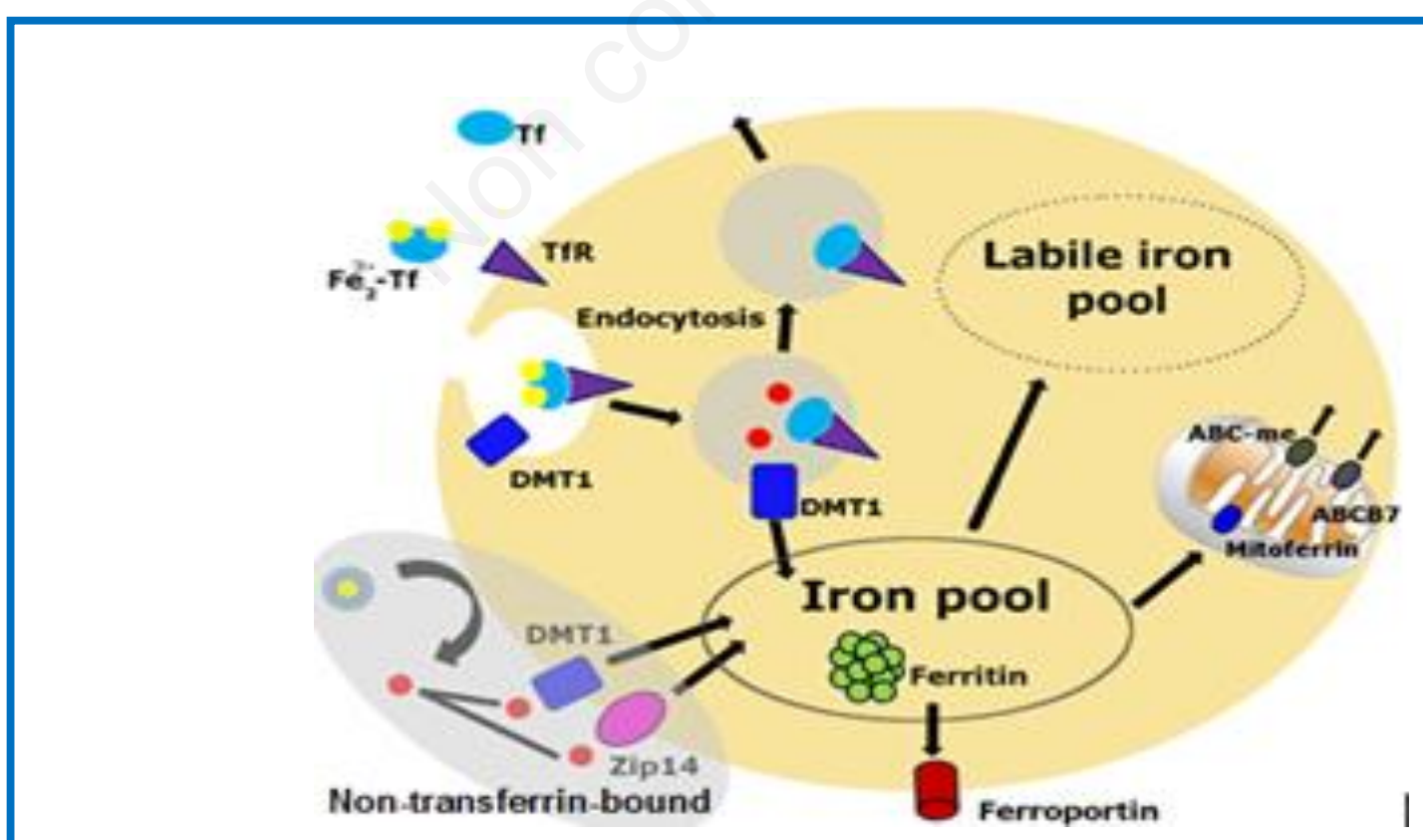

Fig 1. Role of iron 
Zip14 (Slc39a14) deletion. Exp Gerontol 2016;85:88-94. doi: 10.1016/j.exger.2016.09.013. Epub 2016 Sep 16

2. Xu J, Hwang JC, Lees HA, et al. Long-term perturbation of muscle iron homeostasis following hindlimb suspension in old rats is associated with high levels of oxidative stress and impaired recovery from atrophy. Exp Gerontol 2012;47:100-8. doi: 10.1016/j.exger.2011.10.011. Epub 2011 Nov 4.

3. Xu J, Marzetti E, Seo AY, et al. The emerging role of iron dyshomeostasis in the mitochondrial decay of aging. Mech Ageing Dev 2010;131:487-93. doi: 10.1016/j.mad. 2010.04.007. Epub 2010 Apr 29.

4. Seo $A Y, X u J$, Servais $S$, et al. Mitochondrial iron accumulation with age and functional consequences. Aging Cell 2008;7:706-16.

5. Xu J, Knutson MD, Carter CS, Leeuwenburgh C. PLoS One. Iron accumulation with age, oxidative stress and functional decline. 2008;3(8):e2865. doi: 10.1371/ journal.pone.0002865.

$$
* * * * *
$$

\section{Proteostasis and mitochondrial dynamics in aging and muscle wasting}

\section{Marco Sandri $(a, b, c)$}

(a) Department of Biomedical Sciences, University of Padova, Padova, Italy. (b) Venetian Institute of Molecular Medicine, Padova, Italy; (c) Myology Center, University of Padova, Padova, Italy

\section{E-mail: marco.sandri@unipd.it}

Kay Words: Proteostasis, mitochondrial dynamics, aging, muscle wasting

The ability to activate compensatory mechanisms in response to environmental stress is an important factor for survival and maintenance of cellular functions. A system that is often activated both in short and prolonged stress conditions is autophagy lysosome system (Milan et al, 2015). ${ }^{6}$ Autophagy is required to clear the cell from dysfunctional organelles and altered proteins and is reported to decline during ageing. This reduction causes accumulation of abnormal mitochondria and toxic proteins that contribute to precocious ageing sarcopenia (Carnio et al, 2014; Lapierre et al, 2015). ${ }^{7,8}$ Here I'll present the last data about autophagy regulation, the role of autophagosomes in mitochondria turnover and the pathogenetic implications of deregulated autophagy in sarcopenia and in skeletal- to cardiac-muscle cross talk.

6. Milan $G$, Romanello V, Pescatore F, et al. Regulation of autophagy and the ubiquitin-proteasome system by the FoxO transcriptional network during muscle atrophy. Nat Commun 2015;6:6670.

7. Carnio S, LoVerso F, Baraibar MA, et al. Autophagy impairment in muscle induces neuromuscular junction degeneration and precocious aging. Cell Rep 2014;8:1509. 21.

8. Lapierre LR, Kumsta C, Sandri M, et al. Transcriptional and epigenetic regulation of autophagy in aging. Autophagy 2015;11:867-80.

$$
* * * * *
$$

\section{Skeletal muscle redox homeostasis and weakness in heart failure}

\section{Leonardo Franklin Ferreira}

College of Health \& Health Professions, University of Florida, Gainesville, FL, USA

E-mail:Ferreira@hhp.ufl.edu

Kay Words: Heart failure, diaphragm, oxidants, weakness

Heart failure causes skeletal myopathy that affects both limb and respiratory muscles. The diaphragm is the primary respiratory muscle for inspiration, and in heart failure, abnormalities of the diaphragm occur earlier or to a greater extent than in limb muscles ${ }^{9,10}$ The diaphragm is the main 'pump' contributing to airway clearance (sneezing, coughing), adequate ventilation and gas exchange during physical activity, and reflex activation the sympathetic nervous system. ${ }^{11,12}$ Therefore, neuromuscular integrity of the diaphragm plays a critical role in the integrative pathophysiology of heart failure. The disease disrupts the dynamics of circulating factors (e.g. angiotensin II and cytokines) that trigger pathways involving sphingolipids, reactive oxygen species, and proteolysis leading to diaphragm neuromuscular junction alterations and intrinsic myocyte abnormalities (Fig. 2) ${ }^{13}$ Diaphragm myocyte abnormalities include decreased abundance of metabolic enzymes, oxidation of contractile and EC coupling proteins, fiber atrophy, loss of force, and accelerated fatigue. Our recent data show that effects of heart failure on the diaphragm depend on disease severity, involves a cross-talk between multiple

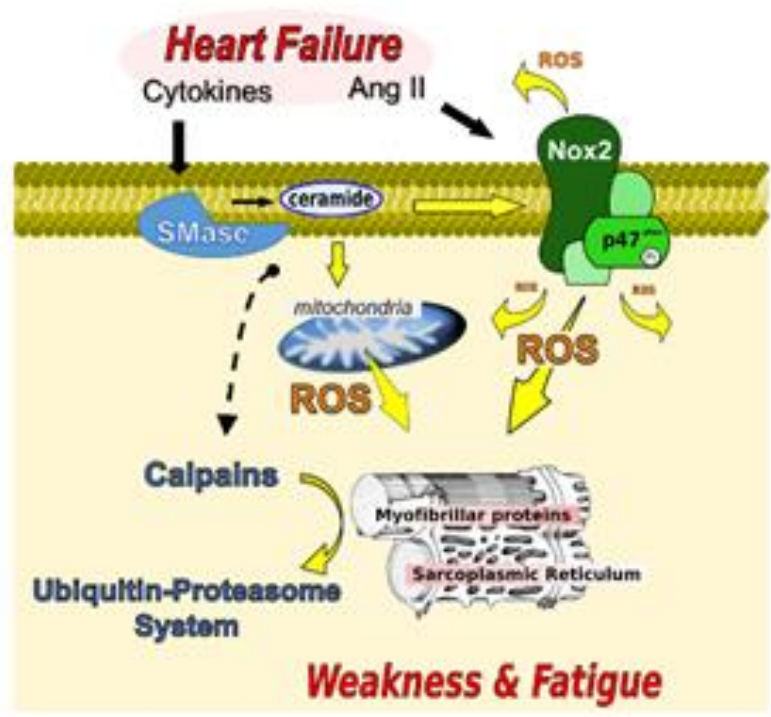

Fig 2. Circulating factors and intra-myocyte pathways leading to diaphragm abnormalities in heart failure. Angiotensin II (Ang II), sphingomyelinase (SMase), NAD $(P) H$ oxidase 2 (Nox2), reactive oxygen species (ROS). Figure reproduced from Kelley \& Ferreira. ${ }^{5}$ 
sources of reactive oxygen species, and reveal changes in the global and thiol redox proteomics associated with loss of diaphragm contractile function.

9. Hammond MD, Bauer KA, Sharp JT, Rocha RD. Respiratory muscle strength in congestive heart failure. Chest 1990;98:1091-4.

10. Howell S, Maarek JM, Fournier M, et al. Congestive heart failure: differential adaptation of the diaphragm and latissimus dorsi. J Appl Physiol 1995;79:389-97.

11. Sieck GC, Fournier M. Diaphragm motor unit recruitment during ventilatory and nonventilatory behaviors. J Appl Physiol (1985) 1989;66:2539-45.

12. Dempsey JA, Romer L, Rodman J, et al. Consequences of exercise-induced respiratory muscle work. Respir Physiol Neurobiol 2006;151:242-50.

13. Kelley RC, Ferreira LF. Diaphragm abnormalities in heart failure and aging: mechanisms and integration of cardiovascular and respiratory pathophysiology. Heart Fail Rev 2017;22:191-207.

14. Dalla Libera L, Ravara B, Gobbo V, et al. A transient antioxidant stress response accompanies the onset of disuse atrophy in human skeletal muscle. J Appl Physiol (1985) 2009;107:549-57. doi: 10.1152/ japplphysiol. 00280.2009. Epub 2009 May 28.

$$
* * * * *
$$

\section{Not all exercises are created equal: the multifaceted} aspect of resistance training

\section{Antonio Paoli}

\section{Department of Biomedical Sciences, University of Padova, Italy}

\section{E-mail: antonio.paoli@unipd.it}

Key Words: Resistance training, muscle hypertrophy, strength, cross sectional area

Resistance training (RT) exerts many of its positive health effects through increase of strength and muscle mass. ${ }^{15}$ Although these two variables are classically considered together (increase of muscle mass leads to an increase of strength, after the first period of neuromuscular adaptation $)^{16,17}$ recently this assumption has been called into question. ${ }^{18}$ Regardless their reciprocal influences both these adaptations (increase of muscle strength and cross sectional area, aka hypertrophy) are induced by RT but they could be of different magnitude in different individuals, thus one other critical issue in the field of RT's research is the existence of responders and nonresponders. In recent years this aspect was brought to attention by several studies, ${ }^{19}$ e.g. Ahtiainen et al. demonstrated a great heterogeneity in muscle mass and strength responses to RT regardless sex and age, ${ }^{20}$ whilst an earlier study showed high responders and low responders in term of muscle fiber CSA after a period of RT. ${ }^{21}$ On the other hand recently Barbalho and colleagues analysing older women, ${ }^{22}$ found that there are no nonresponders both to low or high volume RT. The question is intriguing and probably involves both individual/genetic specificity, ${ }^{23}$

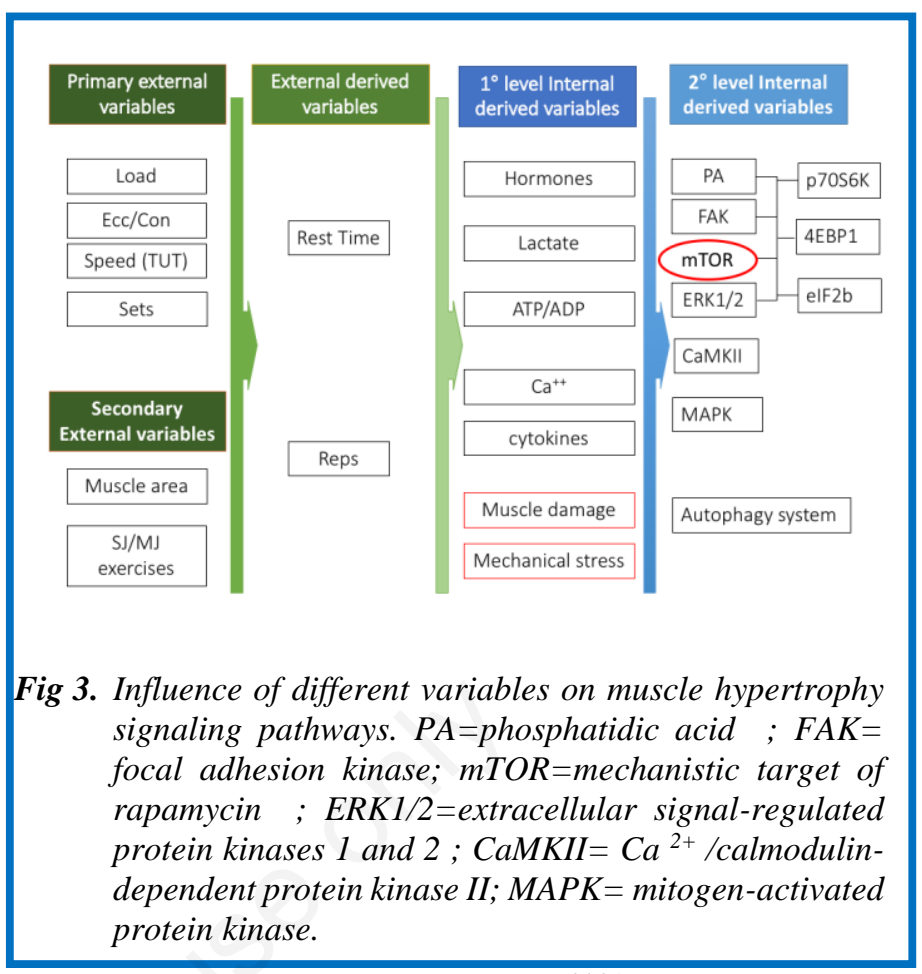

and the numerous variables of RT. ${ }^{24,25}$ In our opinion there is something that maybe best described as a "scotoma" in research on various training methodologies; if we don't consider the extremely wide range of different exercise execution we risk underestimating the importance and the effects of the different kinds of exercise. A resistance training program is a composite of several important variables including: 1) muscle action used, 2) type of resistance used, 3) volume (total number of sets and repetitions), 4) exercises selected and workout structure (e.g., the number of muscle groups trained), 5) the sequence of exercise performance, 6) rest intervals between sets, 7) repetition velocity and 8) training frequency. All these variables may influence muscle response to exercise and may be more effective in one individual compared to another. We recently demonstrated how the manipulation of rest intervals and number of reps could influence cellular signalling and long term muscle response (Figure 3).

15. Kraemer WJ, Adams K, Cafarelli E, et al. American college of sports medicine position stand. Progression models in resistance training for healthy adults. Med Sci Sports Exerc 2002;34:364-80.

16. Moritani T, deVries HA. Neural factors versus hypertrophy in the time course of muscle strength gain. Am J Phys Med 1979;58:115-30.

17. Seynnes OR, de Boer M, Narici MV. Early skeletal muscle hypertrophy and architectural changes in response to high-intensity resistance training. J Appl Physiol (Bethesda, Md 1985) 2007;102:368-73.

18. Dankel SJ, Buckner SL, Jessee MB, et al. Correlations do not show cause and effect: Not even for changes in muscle 
size and strength. Sports Med. 2018;48:1-6. doi: 10.1007/s40279-017-0774-3.

19. Hubal MJ, Gordish-Dressman H, Thompson PD, et al. Variability in muscle size and strength gain after unilateral resistance training. Med Sci Sports Exerc 2005;37: 964-72.

20. Ahtiainen JP, Walker S, Peltonen H. et al. Heterogeneity in resistance training-induced muscle strength and mass responses in men and women of different ages. Age (Dordr) 2016;38:10.

21. Bamman MM, Petrella JK, Kim JS, et al. Cluster analysis tests the importance of myogenic gene expression during myofiber hypertrophy in humans. Journal of applied physiology (Bethesda, Md: 1985) 2007;102:2232-9.

22. Barbalho MSM, Gentil P, Izquierdo M, et al. There are no no-responders to low or high resistance training volumes among older women. Exp Gerontol 2017;99:1826.

23. Timmons JA. Variability in training-induced skeletal muscle adaptation. J Appl Physiol (1985) 2011;110:84653.

24. Paoli A. Resistance training: The multifaceted side of exercise. Am J Physiol Endocrinol Metabol 2012;302 E387.

25. Paoli A, Bianco A. Not all exercises are created equal. Am J Cardiol 2012;109:305. doi: 10.1016/j. amjcard.2011.10.011.

$$
* * * * *
$$

Investigation of the mechanism by which the ERG1a $\mathrm{K}^{+}$channel increases intracellular calcium

Amber L. Pond (a), Evan E Pratt (b), Clayton Whitmore (a), Emily Rantz (b), Amy Salyer (b), Ugo Carraro (c,d,e), Sandra Zampieri (e), Joseph Cheatwood (a), Gregory H Hockerman (b)

(a) Anatomy Dept., Southern Illinois Univ. School of Medicine, Carbondale, IL USA; (b) Medicinal Chemistry and Molecular Pharmacology Dept., Purdue Univ. School of Pharmacy, West Lafayette, IN,USA; (c) IRCCS Fondazione Ospedale San Camillo, VeneziaLido, Italy. (d) A\&CM-C Foundation for Translational Myology, Padova, Italy; (e) Department of Biomedical Sciences, University of Padova, Italy.

\section{E-mail: apond@siumed.edu}

KeyWords: $\quad$ Skeletal muscle, atrophy, ERG1 Potassium Channel, intracellular calcium

Intracellular $\mathrm{Ca}^{2+}(\mu \mathrm{M}$ concentration) is essential for excitation-contraction coupling in skeletal muscle. However, smaller increases (nM) in intracellular calcium concentration $\left(\left[\mathrm{Ca}^{2+}\right] \mathrm{i}\right)$ can contribute to other normal muscle physiological processes in non-contracting muscle; indeed, fluctuations in localized calcium concentration can serve as a second messenger. ${ }^{26}$ In contrast, inappropriate changes in $\left[\mathrm{Ca}^{2+}\right] \mathrm{i}$ can have detrimental effects on muscle tissue and are associated with numerous skeletal muscle pathologies, for example malignant hyperthermia, muscular dystrophy, amyotrophic lateral sclerosis, cancer cachexia, as well as atrophy. ${ }^{27-30}$ Therefore, $\left[\mathrm{Ca}^{2+}\right] \mathrm{i}$ must be tightly regulated in terms of time, space and amplitude for cellular processes to occur in an appropriately coordinated fashion. In earlier reports, we have shown that the ERG1a $\mathrm{K}+$ channel is upregulated in atrophying skeletal muscle and contributes to increased ubiquitin proteasome proteolysis. ${ }^{31}$ Using fura-2 dyes, we have shown that transfection of ERG1a into $\mathrm{C} 2 \mathrm{C} 12$ myotubes results in an increase in basal $\left[\mathrm{Ca}^{2+}\right] \mathrm{i}$ as well as a transient increase in response to depolarization. We explored this transient increase in $\left[\mathrm{Ca}^{2+}\right] \mathrm{i}$ using pharmacological agents and show that the ERG1a-induced increase is not sensitive to the L-type calcium channel blocker nifedipine, suggesting that it does not result from modulation of Cav1.1 channels; however, this increase is sensitive to the SERCA blocking agent thapsigargin, suggesting that the sources of the calcium are the sarcoplasmic reticulum stores. We have explored this further and preliminary data suggest that, relative to control transfected cells, ERG1a expressing myotubes may have a greater concentration of basal IP1, a metabolic product of IP3 which functions in the inositol signaling cascade by binding IP3 receptors to release calcium from the endoplasmic reticulum (Figure 4). In summary, to date the data show that ERG1a increases $\left[\mathrm{Ca}^{2+}\right]$ i levels and suggest that this increase could occur, at least in part, as a result of release of calcium from sarcoplasmic reticulum stores.

26. Bonaldo P, Sandri M. Cellular and molecular mechanisms of muscle atrophy. Disease Models \& Mechanisms 2013;6:25. doi: 10.1242/dmm.010389. Review

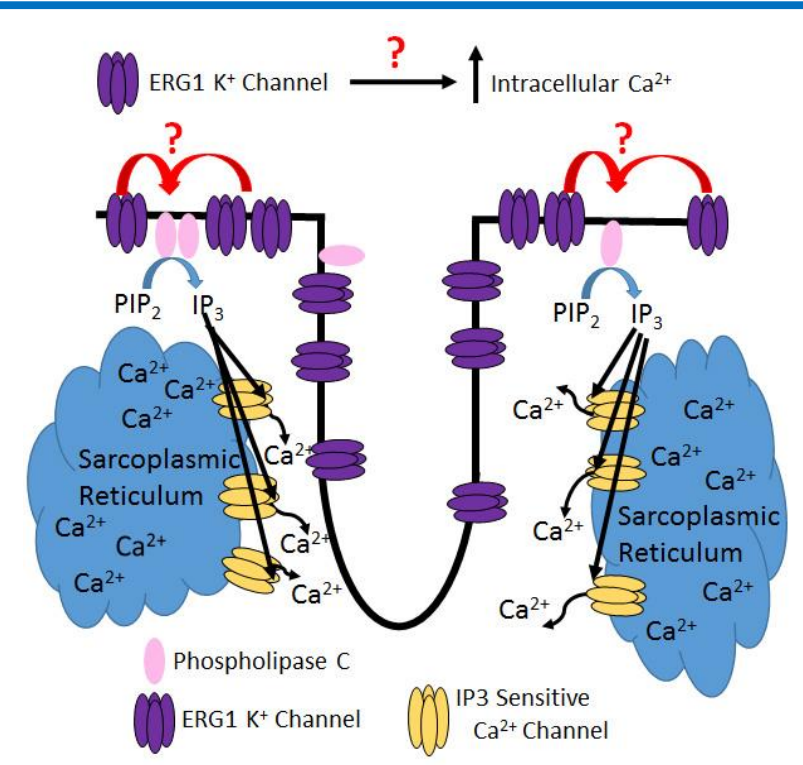

Fig 4. By what mechanism(s) does ERG1 increase intracellular $\mathrm{Ca}^{2+}$ concentration? 
27. Lavorato M, Gupta PK, Hopkins PM, Franzini-Armstrong C. Skeletal muscle microalterations in patients carrying malignant hyperthermia-related mutations of the $e-c$ coupling machinery. Eur J Transl Myol 2016 Sep 15;26:6105. doi: 10.4081/ejtm.2016.6105. eCollection 2016 Sep 15.

28. Missiaen L, Robberecht W, van Den Bosch L, et al. Abnormal intracellular calcium homeostasis and disease. Cell Calcium 2000;28:1.

29. Protasi F. Mitochondria association to calcium release units is controlled by age and muscle activity. Eur J Transl Myol 2015;25:257-62. doi: 10.4081/ejtm.2015.5604. eCollection 2015 Aug 24.

30. Totzeck A, Mummel P, Kastrup O, Hagenacker T. Clinical features of neuromuscular disorders in patients with $N$-type voltage-gated calcium channel antibodies. Eur J Transl Myol 2016;26:5962. doi: 10.4081/ejtm.2016.5962. eCollection 2016 Sep 15.

31. Wang X, Hockerman GH, Green 3rd HW, et al. Mergla K+ channel induces skeletal muscle atrophy by activating the ubiquitin proteasome pathway. FASEB J 2006;20:1531.

$$
* * * * *
$$

\section{ER stress modulation in muscle regeneration}

\section{Catherine Moorwood, Matan Ozery, Elisabeth Barton}

Department of Applied Physiology and Kinesiology, College of Health and Human Performance, University of Florida, Gainesville, FL, USA

\section{E-mail:erbarton@ufl.edu}

Key Words: Caspase-12, muscular dystrophy, acute injury

The endoplasmic reticulum (ER) is the largest membrane system in animal cells and is responsible for processing of membrane and secretory proteins, synthesis of lipids and carbohydrates, glycogen degradation and drug detoxification, as well as maintaining intracellular calcium homeostasis. The ER is specialized in different cell types, and a striking example is the sarcoplasmic reticulum (SR) of muscle, which regulates calcium uptake and release during muscle contraction. When the S/ER is put under stress, which can occur due to a variety of factors, unfolded and misfolded proteins accumulate in the lumen. Cells respond to ER stress by activating the unfolded protein response (UPR), which is comprised of multiple signaling pathways, some of which lead to adaptation, but others to cell death via apoptosis, particularly when ER stress becomes chronic (Figure 4). ${ }^{32,33}$ Importantly, we have recently documented that ER stress is heightened in dystrophic muscles from both human patients and mdx mice. ${ }^{34}$ Further, in the same study, we demonstrated that ablation of Caspase-12, a mediator of the apoptotic response to ER stress (Figure 5 ), improved functional capacity of muscles from adult mdx mice. To determine if this pathway was also contributing to pathology during periods of heightened transient ER stress, we examined the impact of caspase12 ablation on muscles of $\mathrm{mdx}$ mice at the weaning transition, where there is exceptionally high ER stress, and also following acute injury in wildtype mice. Caspase-12 ablation reduced apoptosis and improved soleus function in 4 wk old $\mathrm{mdx}$ mice. Following cardiotoxin injection, there was a transient increase in ER stress markers in the regenerating limb muscles. With Caspase-12 ablation, the muscles tended to resolve damage more rapidly, with larger muscle fibers evident 11 days after cardiotoxin injection, and a $10 \%$ improvement is force generation. Taken together, blockade of the apoptotic arm of ER stress can ameliorate many aspects of dysfunction in both acute and chronic muscle injury.

32. Rutkowski DT, Kaufman RJ. That which does not kill me makes me stronger: adapting to chronic ER stress. Trends Biochem Sci 2007;32:469-76.

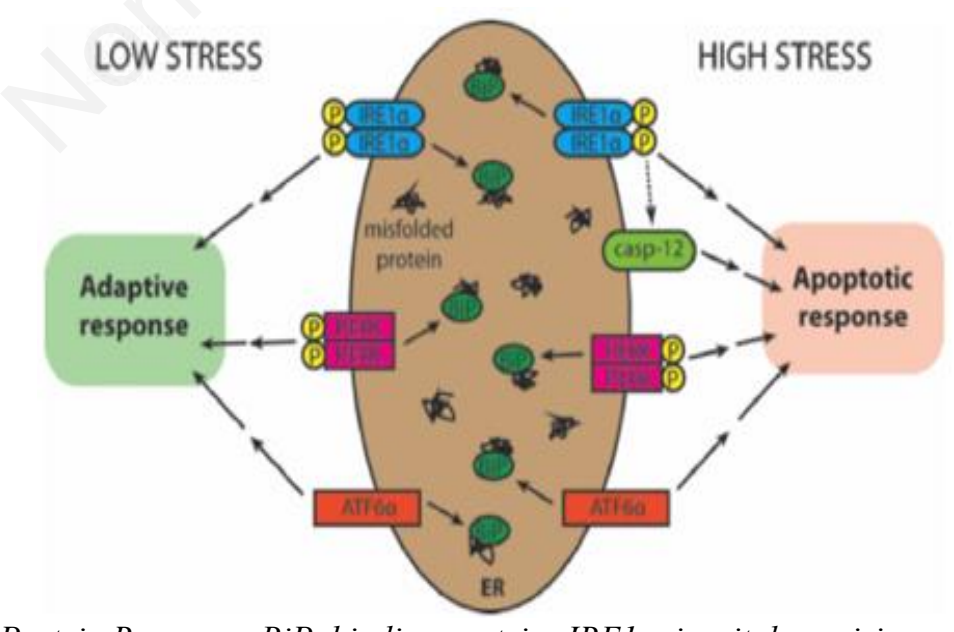

Fig 5. The Unfolded Protein Response. BiP, binding protein; IRE1 $\alpha$, inositol requiring enzyme $1 \alpha$; PERK, protein kinase RNA-like endoplasmic reticulum kinase; ATF6 $\alpha$, activating transcription factor $6 \alpha$; eIF $2 \alpha$, eukaryotic initiation factor $2 \alpha$; XBP-1, X-box binding protein 1; ATF4, activating transcription factor 4; ERAD, ERassociated degradation; casp, caspase; JNK, c-jun N-terminal kinase; CHOP, CCAAT/enhancer binding protein homologous protein. 
33. Szegezdi E, Fitzgerald U, Samali A. Caspase-12 and ERstress-mediated apoptosis: the story so far. Ann NY Acad Sci 2003;1010:186-94.

34. Moorwood C, Barton ER. Caspase-12 ablation preserves muscle function in the mdx mouse. Hum Mol Genet 2014;23:5325-41.

$$
* * * * *
$$

\section{Plasticity and regeneration of the Neuromuscular Junction}

Marco Pirazzini (a), Samuele Negro (a), Ornella Rossetto (1), Michela Rigoni (a), Cesare Montecucco $(a, b)$

(a) Department of Biomedical Sciences, University of Padua, Italy; (b) CNR Institute of Neuroscience, Padua, Italy; (b)Department of Biomedical Sciences, University of Padova, Italy

\section{E-mail:marco.pirazzini@unipd.it}

Key Words: Plasticity, regeneration, neuromuscular junction

The NMJ is the specialized synapse which enables the communication between motor neurons and skeletal muscles. It is formed by the motor axon terminal (MAT) and the muscle fiber (MF), separated by a basal lamina, and by perisynaptic Schwann cells (PSC) that cover the MAT. An intense cross-talk takes place during NMJ maturation, and then a precise orchestration and a fine tuning of these signals maintain the synapse functional for a long time. ${ }^{35,36} \mathrm{NMJs}$ are not protected by anatomical barriers, and are thus exposed to various damages, from traumas to poisons, bacterial and animal neurotoxins, or autoimmune antibodies. This lead to functional or physical denervation of MF and to neuroparalysis. For these reasons and for its essential role in life and survival, the NMJ has retained and refined throughout evolution the capacity to regenerate and remodel (Figure 6). Depending on the nature of the insult, MAT can sprout new nerve terminals and form new synapses with the MF, or even re-form over degenerated MATs novel NMJs that look and perform as the original ones. Despite the wonder and the general importance of these properties, a molecular characterization is still lacking. ${ }^{37}$ To fill this gap, we recently developed a novel experimental approach based on the use of neurotoxins to reversibly degenerate motor nerve terminals and to profile the signals exchanged among MAT, MF and PSC during regeneration ${ }^{38,39}$ by transcriptomics. We found that the chemokine CXCL12 $\alpha$, also known as stromal-derived factor-1 (SDF-1), is specifically produced by PSC following MAT degeneration and, together with its receptor CXCR4, is expressed by regenerating axon terminals, to orchestrate a molecular axis speeding up nerve terminal regeneration.

35. Sanes JR, Lichtman JW. Development of the vertebrate neuromuscular junction. Annu Rev Neurosci 1999;22:389-442.

36. Tintignac LA, Brenner HR, Ruegg MA. Mechanisms Regulating Neuromuscular Junction Development and Function and Causes of Muscle Wasting. Physiol Rev 2015;95:809-52.

37. Rigoni M, Montecucco C. Animal models for studying motor axon terminal paralysis and recovery. $J$ Neurochem 2017;142 Suppl 2:122-29. doi: 10.1111/jnc.13956. Epub 2017 Mar 21. Review.

38. Duregotti E, Negro S, Scorzeto M, et al. Mitochondrial alarmins released by degenerating motor axon terminals

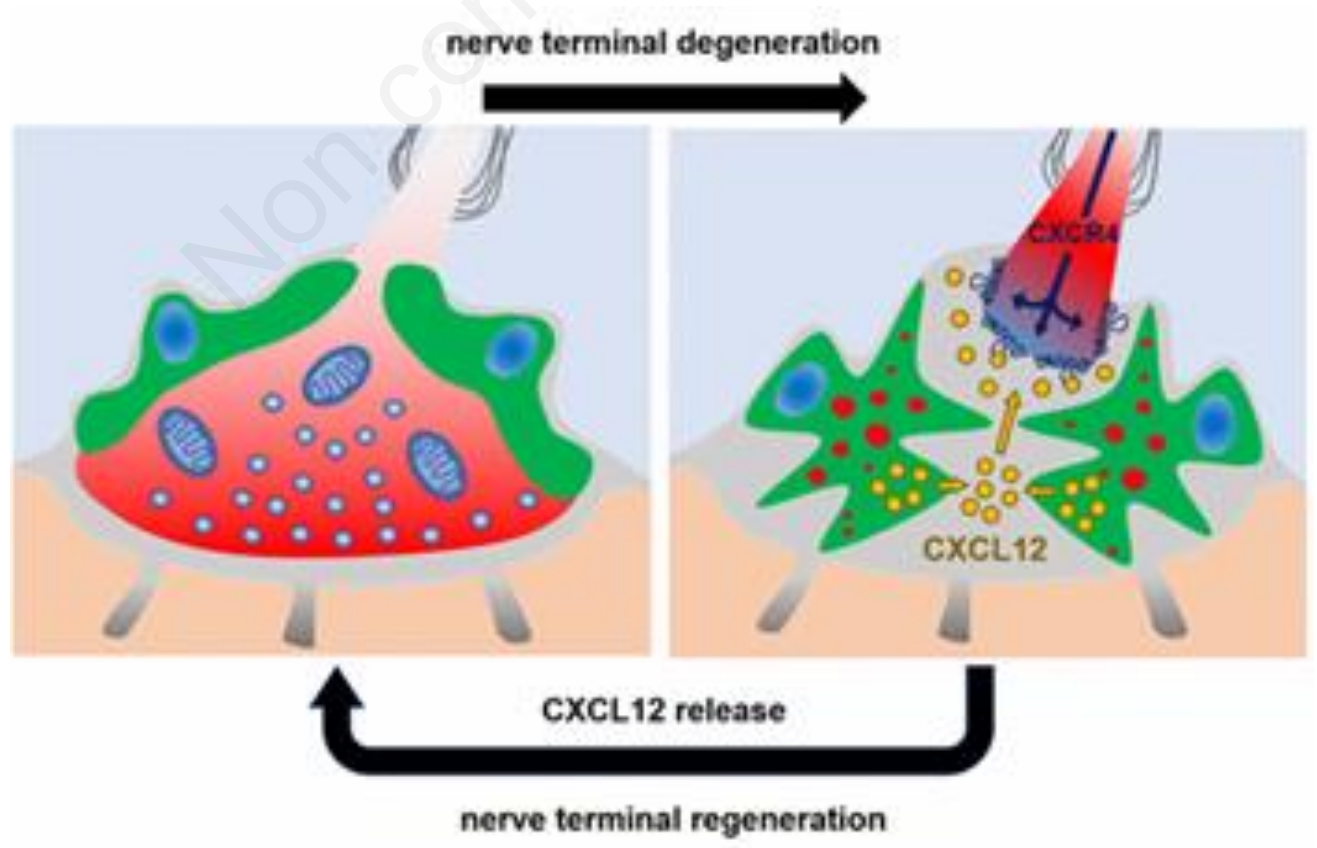

Fig 6. Plasticity and regeneration of the Neuromuscular Junction 
activate perisynaptic Schwann cells. Proc Natl Acad Sci U S A 2015;112:E497-E505.

39. Negro S, Lessi F, Duregotti E, et al. CXCL12alpha/SDF1 from perisynaptic Schwann cells promotes regeneration of injured motor axon terminals. EMBO Mol Med 2017;9:1000-1010. doi: 10.15252/emmm.201607257.

$$
* * * * *
$$

\section{Combination Therapies for Duchenne Muscular Dystrophy}

\section{H. Lee Sweeney, David W. Hammers}

Myology Institute, University of Florida, Gainesville, $F L, U S A$

\section{E-mail: lsweeney@ufl.edu}

Key Words: corticosteroids; myostatin; Duchenne muscular dystrophy; muscle hypertrophy; muscle atrophy

Duchenne muscular dystrophy (DMD) is a caused by loss of the force transmitting and membrane complex organizing protein, dystrophin, and is characterized by progressive muscle deterioration with failed regeneration and replacement with a fatty-fibrous matrix. ${ }^{40} \mathrm{~A}$ number of different targets for aspects of the disease have been identified, which potentially can be used in combination. However, the potential positive and negative interactions of these combinations must first be evaluated. One potential target is myostatin (MSTN) inhibition, which has been shown to increase muscle size and strength and decrease fibrosis in mouse and dog models of Duchenne muscular dystrophy. ${ }^{41,42}$ While human trials using myostatin inhibition in DMD patients are ongoing, there have been no published studies of the potential interactions between glucocorticoid steroids (current standard of care in DMD) and myostatin inhibitors, even though all patients in the current trials are receiving steroid treatments. To address this, we used a severe mouse model of DMD, the mdx mouse on the DBA background, which has heightened inflammation and fibrosis as compared to the more widely utilized $\mathrm{mdx}$ mouse on the C57/B110 background. To this severe mouse model, we administered either prednisolone alone (either $5 \mathrm{mgs} / \mathrm{kg}$ once a day or once a week), MSTN inhibition alone (using AAV-driven secretion of the MSTN propeptide $)^{42}$, or a combination of prednisolone and MSTN inhibition (Figure 7). In agreement with an earlier report, ${ }^{43}$ we observed atrophy in the muscles of mdx mice treated with daily, but not weekly, steroids, and the expected hypertrophy from MSTN inhibition alone. However, the combination of daily steroids and MSTN inhibition either blunted or prevented (depending on the specific muscle) the MSTN-induced hypertrophy. These results suggest that the human DMD trials may not show the same MSTN benefits seen in animal models of DMD if the patients are on daily steroids.

40. Forbes SC, Willcocks RJ, Triplett WT, Rooney WD, Lott $D J$, Wang DJ, Pollaro J, Senesac CR, Daniels MJ, Finkel RS, Russman BS, Byrne BJ, Finanger EL, Tennekoon GI, Walter GA, Sweeney HL, Vandenborne K. PLoS One. 2014 Sep 9;9(9):e106435. doi: 10.1371/journal.pone. 0106435. eCollection 2014. Erratum in: PLoS One. 2014;9(10):e111822. et al. Magnetic resonance imaging and spectroscopy assessment of lower extremity skeletal muscles in boys with Duchenne muscular dystrophy: a multicenter cross sectional study. PLoS One 2014;9: e106435.

41. Wagner KR,McPherron AC, Winik N, Lee SJ. Loss of myostatin attenuates severity of muscular dystrophy in mdx mice. Ann Neurol 2002;52: 832-6.

42. Bish LT, Sleeper MM, Forbes SC, Morine KJ, Reynolds C, Singletary GE, Trafny D, Pham J, Bogan J, Kornegay $J N$, Vandenborne K, Walter GA, Sweeney HL. Long-term systemic myostatin inhibition via liver-targeted gene

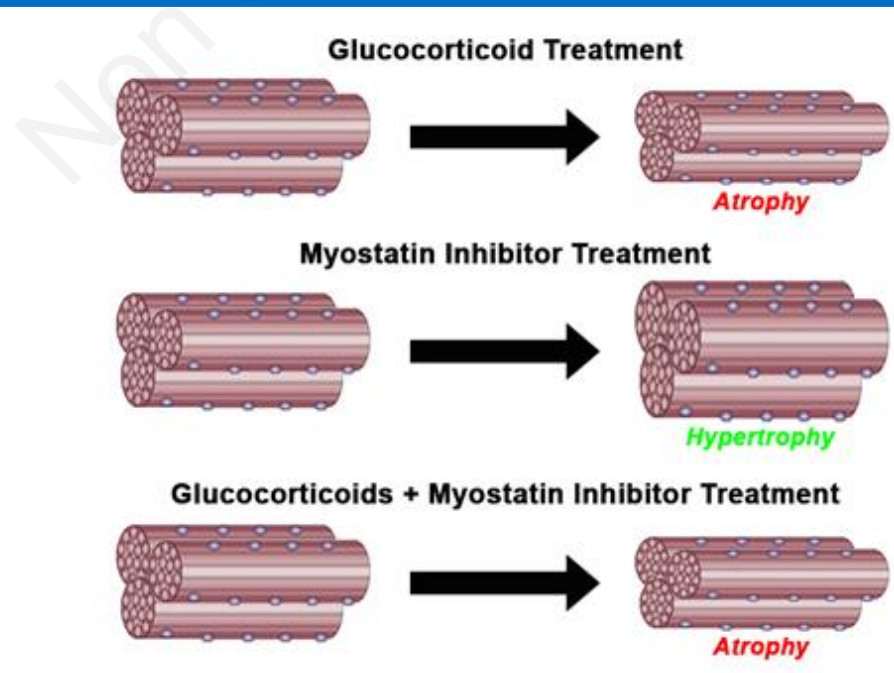

Fig 7. The combination of daily steroids and MSTN inhibition either blunted or prevented (depending on the specific muscle) the MSTN-induced hypertrophy 
transfer in golden retriever muscular dystrophy. Hum Gene Ther 2011;22:1499-509.

43. Quattrocelli $M$, Barefield DY, Warner JL, Vo AH, Hadhazy M, Earley JU, Demonbreun AR, McNally EM. Intermittent glucocorticoid steroid dosing enhances muscle repair without eliciting muscle atrophy. J Clin Invest 2017;127:2418-32.

$$
* * * * *
$$

\section{Phenotypic variablity in Facioscapulohumeral muscular dystrophy}

\section{Sabrina Sacconi,}

Système Nerveux Péripherique, Muscle \& SLA; Pôle de Neurosciences Cliniques, Hôpital Pasteur 2, Nice, France

\section{E-mail: sacconi.s@chu-nice.fr}

Keywords: FSHD, phenotypic variability, SMCHD1, epigenetic

Facioscapulohumeral dystrophy (FSHD -MIM158900) is a frequent inherited myopathy, with a described prevalence ranging between 1:8000 and 1:20.000 (Deenen et al. 2014). ${ }^{44}$ FSHD is clinically well characterized and in most cases can be readily distinguished from other myopathies because of the specific pattern of muscle involvement. In the past decade, major advances have been made in the understanding of the pathophysiological mechanism underlying this disease. FSHD is associated with epigenetic derepression in somatic cells of the highly polymorphic D4Z4 macrosatellite repeat located in the chromosome $4 q$ subtelomere. In the most common form of FSHD, referred to as FSHD type 1 (FSHD1) derepression is caused by a contraction in the number of D4Z4 repeat units (RU) to a size of 1-10 RU. In the control population, the D4Z4 repeat varies between 8 100 RU. In the less frequent form, known as FSHD type 2 (FSHD2), derepression is associated with monoallelic mutations in genes encoding D4Z4 chromatin repressors, most often the structural maintenance of chromatin hinge domain containing 1 gene (SMCHD1; MIM\# 614982) and rarely the DNA methyltransferase 3B gene (DNMT3B; MIM\# 602900) (Lemmers et al; 2012). ${ }^{45}$ In both FSHD1 and FSHD2 the presence of a non-canonical polyadenylation signal (PAS) distally to the derepressed D4Z4 repeat is mandatory to develop the disease. This PAS is only present only on $4 \mathrm{qA}$ subtelomeres (but not on $4 \mathrm{qB}$ subtelomeres, or chromosomes $10 \mathrm{q}$ which carry a highly homologous repeat in their subtelomere) and facilitates the skeletal muscle expression of the DUX4 retrogene of which a copy is located within each unit of the D4Z4 repeat array. DUX4 is a transcription factor normally expressed in the germline and cleavage stage embryos and its ectopic presence in muscle causes the inappropriate activation of a cascade of genes eventually leading to muscles cell death. SMCHD1 is a chromatin repressor acting in specific genomic regions: it is involved in $\mathrm{X}$-chromosome inactivation, and the regulation of some gene clusters and mono-allelically expressed genes (Mason et al, 2017). ${ }^{46}$ Its exact function is unknown, but it likely plays a role in the maintenance of DNA methylation since its dysfunction invariably correlates with reduced DNA methylation at these loci. DNMT3B belongs to the family of DNA methyltransferases and is thought to be primarily

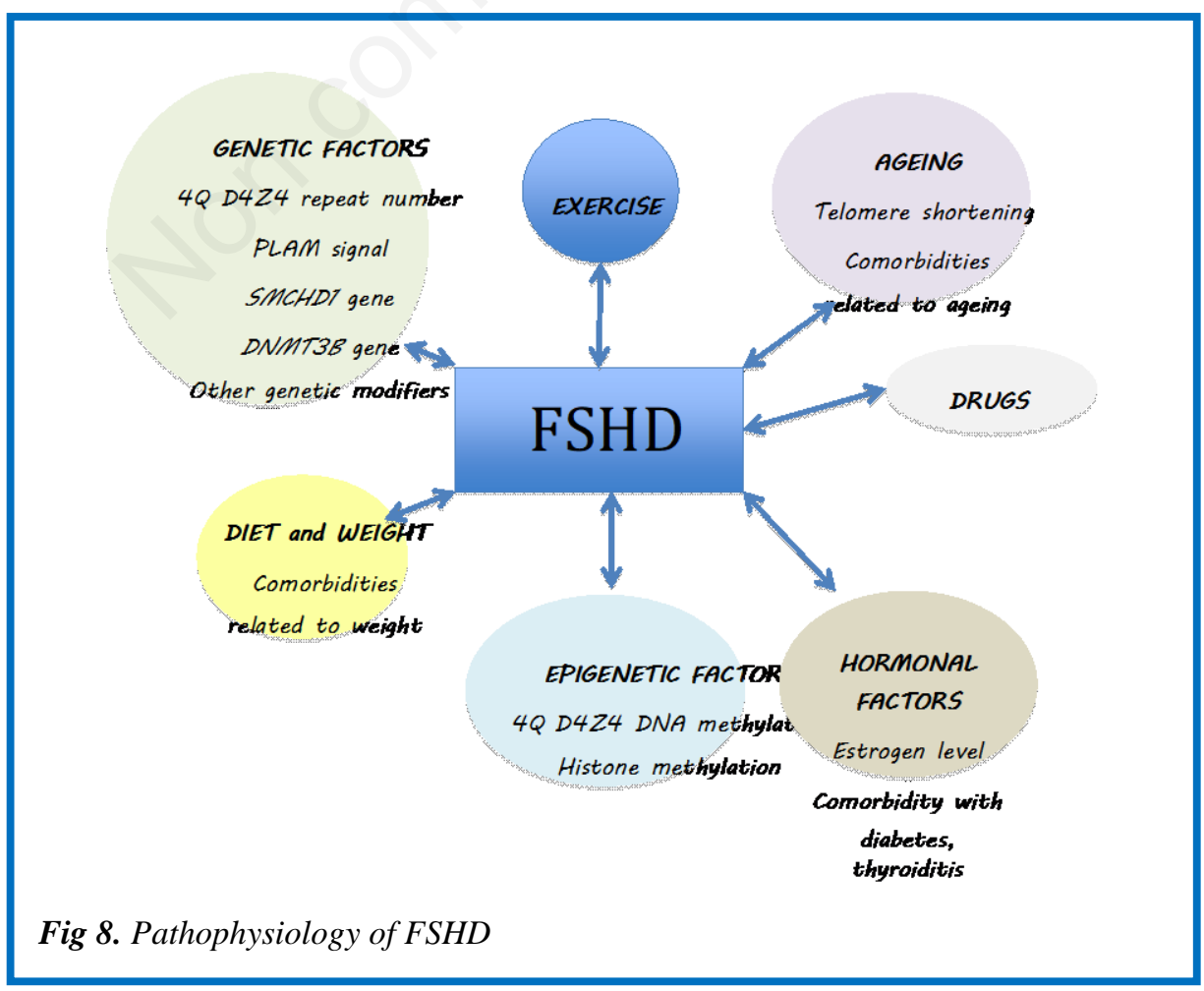


involved in de novo DNA methylation during embryogenesis. A clinical hallmark of FSHD is the marked inter- and intra-familial variability in onset and progression, as well as the presence of atypical clinical phenotypes complicating the diagnosis and genetic counselling of this disease (Figure 8). Phenotypic variability is found in both FSHD1 and FSHD2 and has been related to genetic and epigenetic modifiers of D4Z4 array methylation, (Sacconi et al; 2012) (77 $^{47}$ butso to other factors (hormones, age) (Teveroni et al;2017). ${ }^{48}$ In addition to these modifiers, we will describe some atypical clinical phenotype of FSHD related to large deletion in SMCHD1 gene, (Renerd et al., in press) as well as new phenotype recently associated to mutations in SMCHD1 gene. We will address, the potential consequences of these findings in genetic counselling.

44. Deenen JC, Arnts H, van der Maarel SM, Padberg GW, et al. Population-based incidence and prevalence of facioscapulohumeral dystrophy. Neurology 2014 Sep 16;83:1056-9

45. Lemmers RJ, Tawil R, Petek LM, et al. Digenic inheritance of an SMCHD1 mutation and an FSHDpermissive D4Z4 allele causes facioscapulohumeral muscular dystrophy type 2. Nat Genet 2012;44:1370-4.

46. Mason AG, Slieker RC, Balog J, et al. SMCHD1 regulates a limited set of gene clusters on autosomal chromosomes. Skelet Muscle. 2017;7:12.

47. Sacconi S, Lemmers RJ, Balog J, et al. The FSHD2 gene SMCHD1 is a modifier of disease severity in families affected by FSHD1. Am J Hum Genet 2013;93:744-51.

48. Teveroni E, Pellegrino M, Sacconi S, et al. Estrogens enhance myoblast differentiation in facioscapulohumeral muscular dystrophy by antagonizing DUX4 activity. J Clin Invest 2017;127:1531-45.

$$
* * * * *
$$

Lipolytic studies: beneficial effect of serum deprivation and WY14643 treatment on NLSDM fibroblasts
Sara Missaglia (a,b), Corrado Angelini (c), Elena Maria Pennisi (d), Daniela Tavian $(a, b)$

(a) Laboratory of Cellular Biochemistry and Molecular Biology, CRIBENS, Catholic University of the Sacred Heart, Milan; (b) Psychology Department, Catholic University of the Sacred Heart, Milan; (c) IRCCS Fondazione Ospedale S. Camillo, Venice; (d) UOC Neurologia, San Filippo Neri hospital, Rome, Italy

\section{E-mail:daniela.tavian@unicatt.it}

Key Words: Neutral lipid storage disease, myopathy, lipase, triacylglycerol, lipid droplets, WY-14643

Mutations in the PNPLA2 gene cause the onset of Neutral Lipid Storage Disease with Myopathy (NLSDM), a rare autosomal recessive disorder characterized by an abnormal accumulation of triacylglycerol into cytoplasmic lipid droplets (LDs). ${ }^{49}$ PNPLA2 codes for adipose triglyceride lipase (ATGL), an enzyme that hydrolyses fatty acids from triacylglycerol. NLSDM patients are mainly affected by progressive myopathy, cardiomyopathy, diabetes, hepatomegaly, chronic pancreatitis and short stature. However, their clinical severity appears to be highly variable. Indeed, cardiomyopathy was lethal in some patients or necessitated cardiac transplantation, but older patients have been described with less severe involvement. ${ }^{50-52}$ No specific therapy is currently available. Through functional studies, we have previously demonstrated that some ATGL mutated proteins, identified in our patients, severely diminish lipase activity, but are able to bind to LDs, while some others are truncated proteins with total loss of lipase function. ${ }^{50,53}$ Skin biopsies have been obtained from eight NLSDM patients and skin fibroblasts have been established from these biopsies following standard procedures (Table 1). Fibroblasts were expanded and

Table 1. Primary dermal NLSDM fibroblasts obtained from skin biopsies

\begin{tabular}{|c|c|c|c|c|}
\hline Family & Patients & cDNA & Protein & Reference \\
\hline I & 1 & c. $662 \mathrm{G}>\mathrm{C}$ & R221P & Tavian et al, 2012 \\
\hline \multirow[t]{2}{*}{ II } & 2 & c.541delCA & I212X & Campagna et al, 2008 \\
\hline & & c. $177 \mathrm{~T}>\mathrm{G}$ & L56R & \\
\hline \multirow[t]{2}{*}{ III } & 3 & & & Missaglia et al, 2015 \\
\hline & & c. $577 \mathrm{~A}>\mathrm{T}$ & I193F & \\
\hline \multirow[t]{2}{*}{ IV } & 1 & c.41_47delGCTGCGG & G14Afs75X & Pasanisi et al, 2016 \\
\hline & & c. $696+4 A>G$ & & \\
\hline \multirow[t]{2}{*}{ V } & 1 & & no protein & Missaglia et al, 2016 \\
\hline & & _565delGTCCCCCTT & & \\
\hline
\end{tabular}


cultured in growth medium (Earle's MEM with 10\% FBS) at $37^{\circ} \mathrm{C}$ in a $5 \% \mathrm{CO} 2$ incubator. Four different lines of NLSDM fibroblasts have been used to test the efficiency of some drugs (WY-14643, Clenbuterol, Salmeterol) to reverse the disease phenotype, promoting in vitro TAG breakdown. These cell lines were specifically selected so that two of them were completely lacking ATGL activity (carrying deleterious PNPLA2 mutations, group A), while the others two showed only a reduction of ATGL lipase function (carrying PNPLA2 missense mutations, group B)..$^{5}$ The effects of 70, 100 and $200 \mu \mathrm{M}$ WY-14643 on NLSDM fibroblasts grown in Earle's MEM medium with 3 or $10 \%$ FBS for $96 \mathrm{~h}$ were evaluated by intracellular TAGs detection. Biochemical lipase assays and immuno fluorescence analyses of LDs number and dimension were performed before and after treatment. WY-14643 $200 \mu \mathrm{M}$ was extremely toxic to NLSDM fibroblasts grown with $3 \%$ and $10 \%$ FBS. $100 \mu \mathrm{M}$ treatment with $3 \%$ FBS was toxic, for most of the fibroblast cellular lines. On the contrary, it was found that WY-14643 $70 \mu \mathrm{M}$ treatment (with $3 \%$ of FBS) significantly decreased the intracellular TAG content in NLSDM fibroblasts carrying missense mutations, group $\mathrm{B}$ (TAG content: $\mathrm{P}<0.05$; Lipid droplet area: $\mathrm{P}<0.05$; number of lipid droplet per cell: $\mathrm{P}<0.05)$. No treatment dependent effect was detected in NLSDM fibroblasts characterized by deleterious PNPLA2 mutations (group A). Data obtained from the experiments have been evaluated using using $\mathrm{x}$ 2-squared test. Finally, Salmeterol $(100 \mathrm{nM})$ or Clenbuterol $(1 \mathrm{uM})$ were added to medium (10\% FBS) for $168 \mathrm{~h}$. Clenbuterol resulted in a reduction of TAG content, while Salmeterol was not effective. Further experiments using different dose of Salmeterol or Clenbuterol (with 3\% FBS) are needed to verify whether these compounds can activate intracellular lipolysis. Collectively, data from this study show that NLSDM fibroblasts can be used as disease model to evaluate pharmacological treatments. The PPAR $\alpha$ agonist WY-14643 seems to increase TAG mobilization in NLSDM fibroblasts maintained in low serum concentration.

49. Fischer J, Lefèvre C, Morava E, et al. The gene encoding adipose triglyceride lipase (PNPLA2) is mutated in neutral lipid storage disease with myopathy. Nat Genet, 2007;39:28-30.

50. Tavian D, Missaglia S, Redaelli C, et al. Contribution of novel ATGL missense mutations to the clinical phenotype of NLSD-M: a strikingly low amount of lipase activity may preserve cardiac function. Hum Mol Genet, 2012;21:5318-28.

51. Campagna F, Nanni L, Quagliarini F, et al. Novel mutations in the adipose triglyceride lipasi gene causing neutral lipid storage disease with myopathy. Biochem Biophys Res Commun, 2008;377:843-6.

52. Missaglia S, Tasca E, Angelini C, et al. Novel missense mutations in PNPLA2 causing late onset and clinical heterogeneity of neutral lipid storage disease with myopathy in three siblings. Mol Genet Metab,2015;115:110-7.
53. Pennisi EM, Arca M, Bertini E, et al. Neutral Lipid Storage Diseases: clinical/ genetic features and natural history in a large cohort of Italian patients. Orphanet $J$ Rare Dis, 2017;12:90.

$$
* * * * *
$$

An up-date on LGMD and Becker dystrophies

\section{Corrado Angelini}

IRCCS Fondazione Ospedale San Camillo, Venice-Lido, Italy

E-mail: corrado.angelini@ospedalesancamillo.net

Key Words: LGMD, Becker Dystrophies, HyperCKemia, muscle MRI imaging.

LGMDs is an heterogeneous group of muscle disorders, that includes a number of different forms with dominant inheritance and other forms characterized by recessive inheritance. An ENMC meeting was held in March 2017 in Naarden and revised their classification naming autosomal dominant LGMD D and numbering them 1 to 5 and the recessive forms $\mathrm{R}$ with numbers 1 to 23.Ths classification has included dystrophies with proximal or disto-proximal presentation with evidence in biopsy of fiber degeneration and splitting, high CK, MRI imaging consistent with degenerative change, fibro-fatty infiltration. Overall, LGMDs constitute a considerable fraction of all dystrophic patients and their prevalence ranges from about 8 to 70 cases per million inhabitants $(1: 123,000-1: 14,500)$ depending on the geographical and the ethnic origin. The frequency of each form of LGMD is variable in different populations. Calpainopathy is the most prevalent in the majority of countries, ${ }^{54}$ but frequency ranges from about $10 \%$ of LGMD cases in the United States, to $80 \%$ in Basque country and Russia. Calpainopathy and Dysferlinopathy account for about $50 \%$ of total cases and primary sarcoglycanopathies are about $10-15 \%$ of cases. Clinical features and frequency in Italy have been reported by Magri et al. ${ }^{55}$ The term LGMD defines a progressive weakness with onset in the proximal limb girdle muscles, with age at onset of symptoms varying from early childhood (not congenital) to late adulthood. The progression of muscle weakness is usually symmetrical and variable among individuals and genetic type. The term LGMD used to molecularly classify the disease, becomes inappropriate for many patients when it is utilized to describe the clinical severity. Indeed, these disorders present a wide spectrum of muscle involvement and wasting, spanning from very severe forms, such as those with childhood onset and rapid progression, to relatively benign forms with late onset. The clinical phenotypes due to mutation in the LGMD genes include severe childhood-onset forms, distal and proximal myopathies, pseudo-metabolic myopathies, eosinophilic myositis, and hyperCKemia. Furthermore, patients with a clinically typical LGMD phenotype might carry mutations in the gene encoding emerin, which usually cause Emery-Dreifuss muscular 


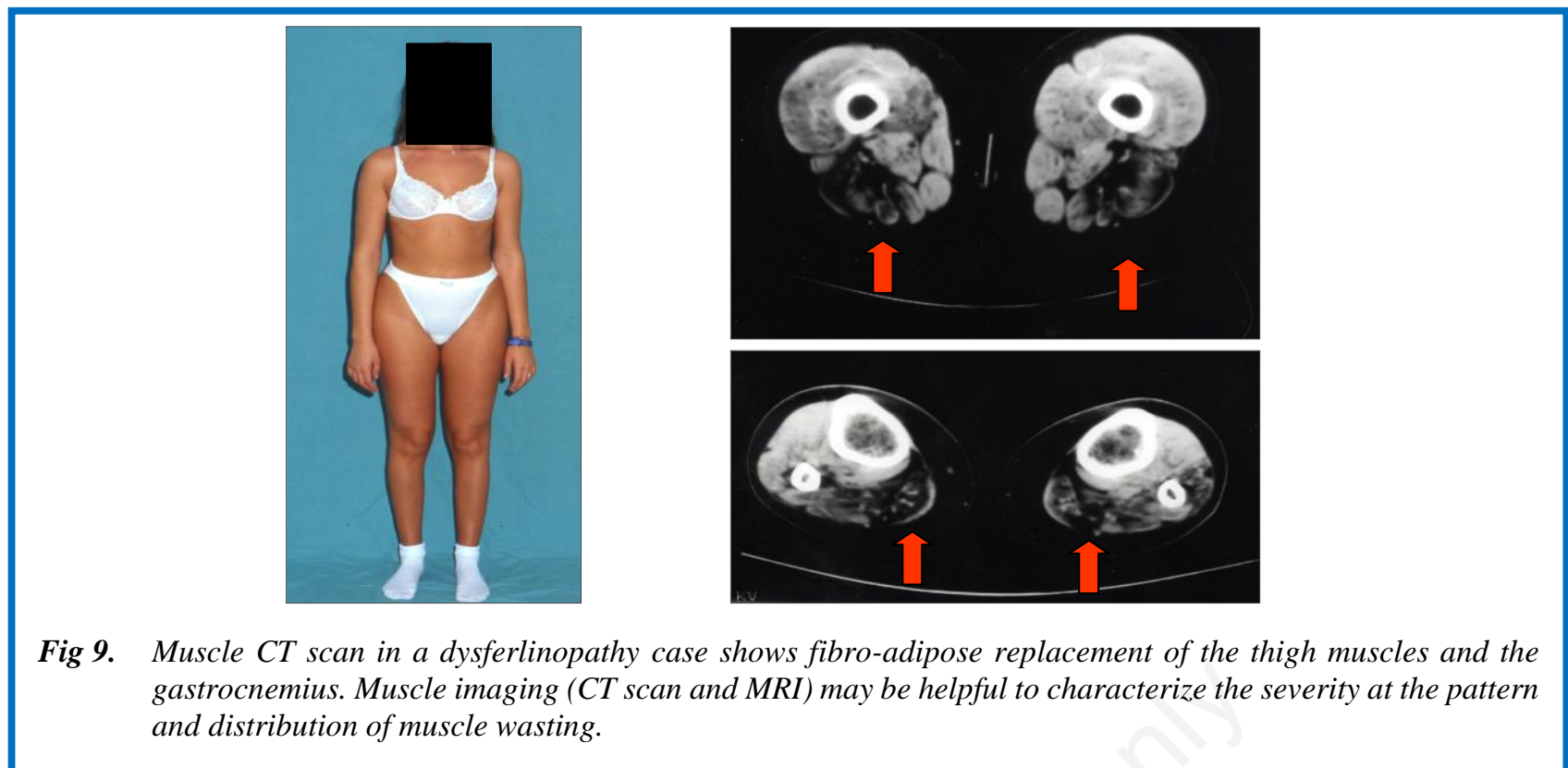

dystrophy (EDMD) phenotype. Because there is a spectrum of phenotypes under the same genetic entity, and a wide genetic heterogeneity under the same phenotype, it is crucial to identify suitable selection criteria to be used when screening patients for the proteins and genes responsible for LGMD. Since LGMD is relatively rare in most populations, other more likely diagnoses need to be excluded. Dystrophinopathies (Duchenne dystrophy, Becker dystrophy, female carriers of Duchenne dystrophy) are the most relevant, and these diagnoses can be ruled out based on dystrophin protein testing and/or DNA mutation analysis in the dystrophin gene. BMD, which is characterized by an X-linked slowly progressive muscle weakness and often cardiac involvement, ${ }^{56,57}$ and is due to mutations in the dystrophin gene (X-linked). There are clinical cases of BMD that are oligosyntomatic and manifest only with cramps and myalgia. Muscle imaging (CT scan and MRI) may be helpful to characterize the severity and the pattern and distribution of muscle wasting (Figure 9). The milder the symptoms are the more difficult is the diagnosis. In both LGMD and BMD our laboratory has evaluated the use of microRNA as biomarkers of disease evolution and correlated their elevation with pattern of muscle imaging. Specific patterns will be presented. Therapy is still an unresolved problem in LGMD and up to now limited to rehabilitation, clinical follow up with cardiologic and respiratory complications. In BMD the use of ACE inhibitors, steroid and cardiac transplantation is possible..$^{58}$

54. Angelini C, Fanin M. Calpainopathy. In: Adam MP, Ardinger HH, Pagon RA, Wallace SE, Bean LJH, Mefford HC, Stephens K, Amemiya A, Ledbetter N, editors. GeneReviews ${ }^{\circledR}$ Seattle (WA): University of Washington, Seattle; 1993-2017. 2005 [updated 2017].

55. Magri F, Nigro V, Angelini $C$, et al. The italian limb girdle muscular dystrophy registry: Relative frequency, clinical features, and differential diagnosis. Muscle Nerve 2017;55:55-68. doi: 10.1002/mus. 25192.

56. Bello L, Campadello P, Barp A, et al. Functional changes in Becker muscular dystrophy: implications for clinical trials in dystrophinopathies Sci Rep 2016;6:32439. doi: 10.1038/srep32439.

57. Barp A, Bello L, Politano L, et al. Genetic Modifiers of Duchenne Muscular Dystrophy and Dilated Cardiomyopathy. PLoS One 2015;10:e0141240.

58. Melacini $P$, Fanin $M$, Angelini A, et al. Cardiac transplantation in a Duchenne muscular dystrophy carrier. Neuromuscul Disord 1998;8:585-90.

$$
* * * * *
$$

\section{Neuronal NOS dysfunction in muscle wasting Luisa Gorza \\ Department of Biomedical Sciences, University of Padova,Italy}

\section{E-mail: luisa.gorza@unipd.it}

Key Words: nNOS; muscle unloading; muscle disuse; muscle atrophy; FoxO3; oxidative stress.

In skeletal myofibers, the large majority of the neuronal isoform of NO synthase (nNOS) localizes in the subsarcolemmal region, participating to the dystrophinglycoprotein complex (DGC). In muscle dystrophies, due to DGC disruption, but also in acquired neuromuscolar disorders, nNOS expression levels and subcellular distribution appear severely affected. The enzyme untethers from the sarcolemma and relocalizes in the sarcoplasm. In the absence of dystrophin, nNOS protein levels appear also severely reduced. Consequences of nNOS sarcoplasmic accumulation on muscle function vary, from no effect, to loss of force, and wasting. During muscle disuse/unloading, nNOS sarcoplasmic redistribution fosters nitrosative and oxidative stress, 
which exerts a further detrimental effect on myofiber atrophy, in concert with upregulation of "atrogenes", increased proteolysis, and arrest of protein synthesis. ${ }^{59-61}$ Attenuated or absent muscle atrophy is observed by combining disuse/unloading either with nNOS knockout, or enzyme inhibition, or pharmacological treatments that preserve nNOS sarcolemmal localization (Figure 10) ${ }^{61-64}$ Nevertheless, the actual role of nNOS subcellular redistribution in disuse muscle atrophy development remains still questionable, since the majority of studies investigated disused, atrophic muscles. Recent results obtained in collaboration with S. Gastadello (Karolinska Institutet, Stockholm) and concerning disused, nonatrophic muscles, from both humans and laboratory rats, indicate that nNOS dysregulation plays an initiating role in atrophy development. Before the onset of myofiber atrophy, the active enzyme redistributes from the subsarcolemma to the sarcoplasm, and transcript and protein levels display a significant, albeit transient, reduction. Furthermore, the early subcellular redistribution of active nNOS molecules occurs concomitantly with the increase of the translocation of the pro-"atrogene" transcription factor FoxO3 into myofiber nuclei. Additional evidence will be provided to demonstrate the requirement of active nNOS molecules to unloading-induced FoxO3 activation.
59. Bonaldo $P$, Sandri M. Cellular and molecular mechanisms of muscle atrophy. Dis Model Mech 2013;6:25-39.

60. Powers SK, Morton AB, Ahn B, et al. Redox control of skeletal muscle atrophyforce and atrophy of hindlimb unloaded rat soleus by hampering neuronal nitric oxide synthase untethering from sarcolemma. J Physiol 2014; 592: 2637-2652.. Free Radic Biol Med 2016;98:208-17.

61. Suzuki N, Motohashi N, Uezumi A, et al. NO production results in suspension induced muscle atrophy through dislocation of neuronal NOS. $J$ Clin Invest 2007;117:2468-76.

62. Vitadello $M$, Gherardini J, Gorza L. The stress protein/chaperone Grp94 counteracts muscle disuse atrophy by stabilizing subsarcolemmal neuronal nitric oxide synthase. Antioxid Redox Signal 2014;20:24792496

63. Lawler JM, Kunst M, Hord JM, et al. EUK-134 ameliorates nNOSmu translocation and skeletal muscle fiber atrophy during short-term mechanical unloading. Am J Physiol Regul Integr Comp Physiol 2014;306:R470-R482.

64. Vitadello M, Germinario E, Ravara B, et al. Cellular and molecular mechanisms of muscle atrophy. Dis Model Mech 2013;6:25-39.

$$
* * * * *
$$

Single fiber proteomics in muscle plasticity and disease

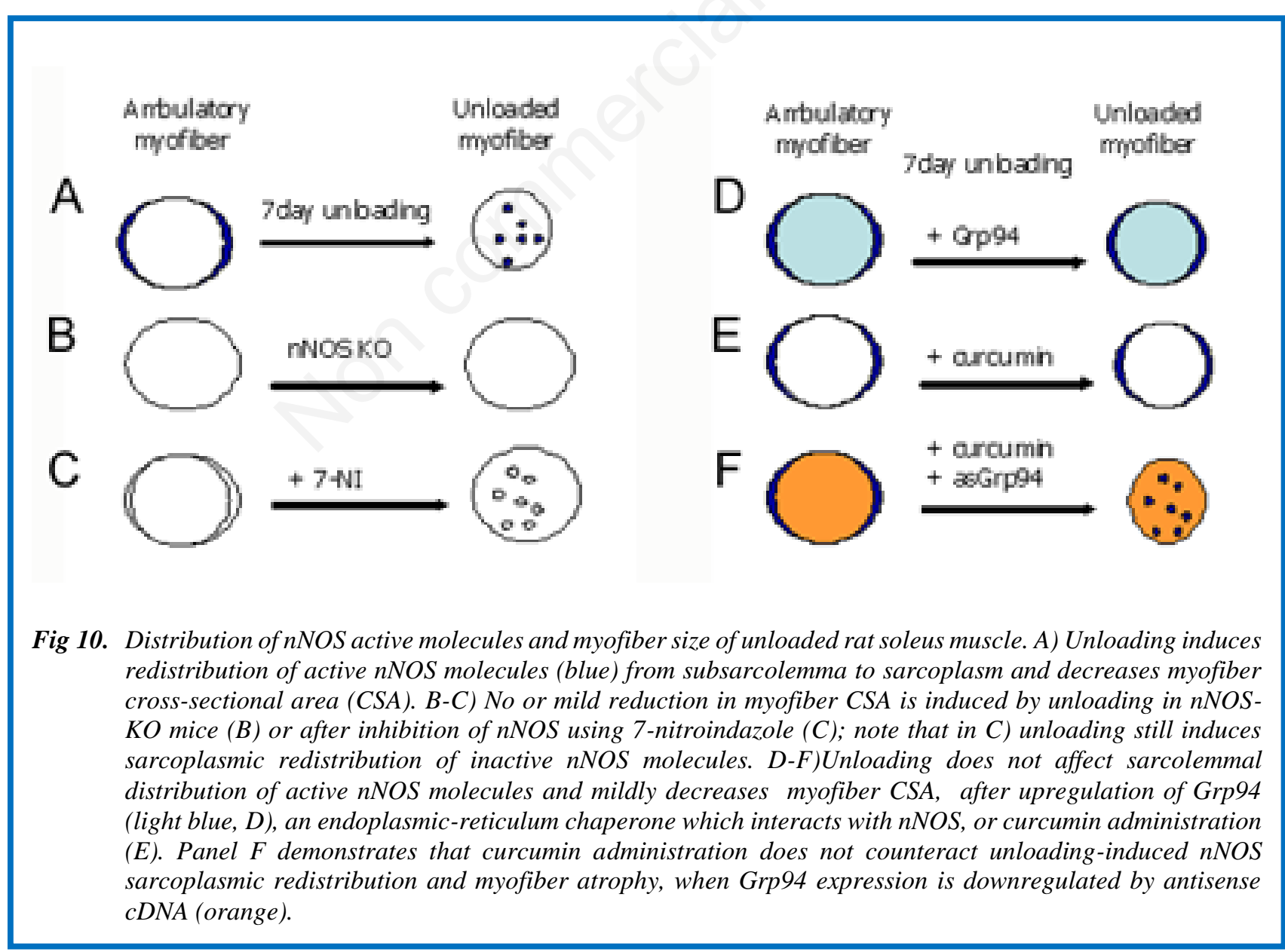


Marta Murgia (a,b), Jing Ta (c), Sophia Doll(b), Philipp Geyer(b), Thomas Klopstoc (c), Matthias Mann (b)

(a) Department of Biomedical Sciences, University of Padova, Italy; (b) Max-Planck-Institute of

Biochemistry, Martinsried, Germany; (c) Department of Neurology, Friedrich-Baur Institute, LudwigMaximilians-Universität, Munich, Germany Email: marta.murgia@unipd.it

KeyWords: Single fiber proteomics, muscle, plasticity, disease

We have designed a mass spectrometry (MS)-based proteomic workflow that can extract large amounts of biological information from minute amounts of frozen muscle biopsies, laser-microdissected muscle fiber sections and freshly isolated single fibers. We first built a fixed resource consisting of deep human skeletal muscle proteomes which we used as libraries of identified peptide features. We then carried out singleshot MS analyses of laser-microdissected sections of single fibers and manually microdissected single fibers from human biopsies (Figure 11). ${ }^{65-67}$ Using the computational proteomics tool MaxQuant, we boosted protein identification in the patients' samples by matching their peptide features to the libraries. With our workflow, triplicate proteome analyses of few micrograms of tissue from one patient can be carried out with minimized hands-on and machine time, yielding quantitative and molecularly defined information. We have applied our proteomic platform to mitochondrial disorders, a particularly complex and heterogeneous group of disorders characterized by mutations in mitochondrial DNA (mtDNA) or in nuclear mitochondrial genes. This leads to a plethora of multisystemic disorders that may literally manifest with any symptom, in any organ, and at any age. Quantitative proteomics may help to bridge the gap between genotype and phenotype and to tackle unsolved questions in mitochondrial medicine. Using the combined cytochrome oxidase/succinate dehydrogenase (COX/SDH) staining, an important diagnostic signpost to indicate mitochondrial defects, we here use laser capture microdissection (LCM) to separate pools of $\mathrm{COX}+$ and COX- muscle fibers from patients suffering from chronic progressive external ophthalmoplegia (CPEO), the disease in which this heterogeneity was initially identified. Our results reveal compensatory mechanisms for the energy deficit caused by mitochondrial defects and suggest novel causal relationships to disease in patients.

65. Toniolo L, Nagaraj N, Ciciliot S, et al. Single Muscle Fiber Proteomics Reveals Fiber-Type-Specific Features of Human Muscle Aging. Cell Rep 2017 Jun 13;19(11):2396-2409

66. Deshmukh AS, Murgia M, Nagaraj N, et al. Deep proteomics of mouse skeletal muscle enables quantitation of protein isoforms, metabolic pathways, and transcription factors. Mol Cell Proteomics 2015;14:84153.

67. Murgia M, Nagaraj N, Deshmukh AS, et al. Single muscle fiber proteomics reveals unexpected mitochondrial specialization. EMBO Rep 2015;16:387-95.

$$
* * * * *
$$

\section{The role of Transportin 3 (TNPO3) in Limb-girdle Muscular Dystrophy 1F, LGMD1F}

Maria Teresa Rodia (a), Roberta Costa (a), Valentina Papa (a), Valentina Pegoraro (b , Laura Giaretta (b),

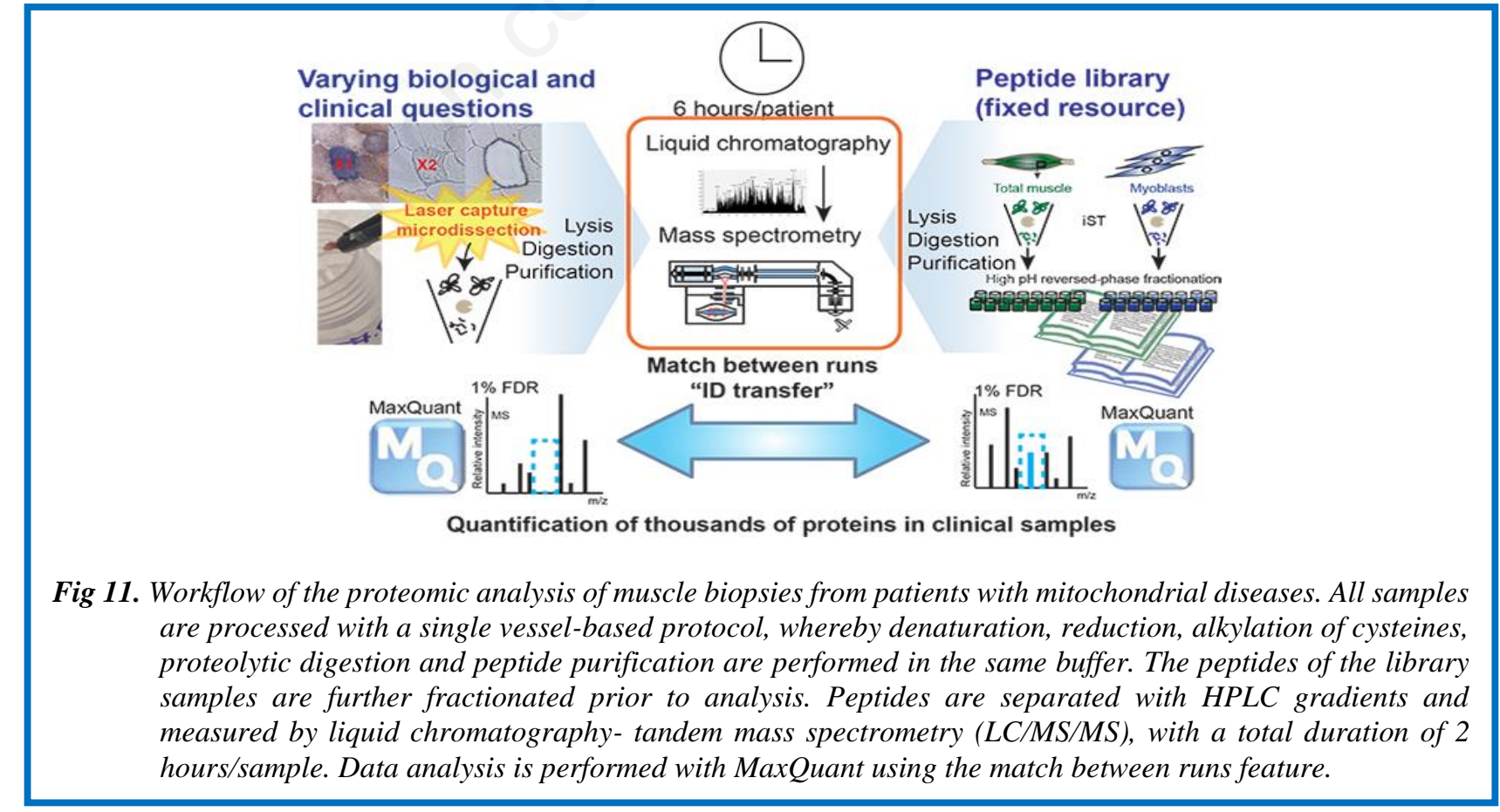


Roberta Marozzo (b), Corrado Angelini (b), Giovanna Cenacchi (a)

(a) Department of Biomedical and Neuromotor Sciences, Alma Mater University of Bologna, Italy; (b) IRCCS Ospedale San Camillo, Venezia, Italy.

Email: giovanna.cenacchi@unibo.it

Key Words: Transportin 3 (TNPO3), Limb-girdle Muscular Dystrophy $1 F, L G M D I F$

Limb-girdle Muscular Dystrophy $1 \mathrm{~F}$ (LGMD1F) is a rare neuromuscular disorder with autosomal dominant inheritance firstly identified in a large Italo-Spanish kindred. Different studies have lead to description of clinical, histological and genetic features of this disorder. The clinical investigation revealed a variable age of onset and different degree of impairment of pelvic girdle muscles that, in more advanced stages of the disease, involves also muscles of axial and upper girdle. However the common feature is a generalized atrophy of muscle mass, confirmed also by histological and ultrastructural analyses. Over the years, scientists clarified the genetic cause of LGMD1F, but key mechanisms of the pathological process have not yet been clarified. Genetic investigation, through whole genome sequencing analysis of DNA from affected subjects, identified a heterozygous mutation in the termination codon of the TNPO3 gene. The mutation consist in a single deletion in the TAG stop codon that results in extension of the reading frame by 15 codons, thus leading to a mutated protein with 15 additional aminoacids at the C-terminus. The sequence analysis also shows that the mutation segregates with the chromosome 7q32.1-32.2. This gene encodes for Transportin 3, a karyopherin- $\beta$ protein directly involved in protein translocation from cytoplasm to the nucleus (Figure 12). The role of TNPO3 in muscle is unknown, but its involvement in nuclear import of protein, also involved in RNA splicing, leads to different hypothesis about how TNPO3 mutation can cause LGMD1F. ${ }^{68-73}$ For example, the mutation could block the whole activity of TNPO3 or make it unable to interact with its cargo proteins, causing the block of the nuclear import of a pattern of proteins involved in RNA splicing. Consequently, this would lead to altered synthesis of cytoskeletal and myofibrillar proteins probably causing disarray of the normal muscle fiber architecture. We have studied the expression of TNPO3 in murine and human myoblasts which, under appropriate culture conditions, differentiate into myocytes; myogenic differentiation was confirmed by the expression of specific differentiation markers (myogenic regulatory factors, desmin and myosin). We evaluated TNPO3 expression at different time points (early, middle and late) during myogenic differentiation and we observed a similar behaviour for both murine and human cells. In the early phase of cell differentiation TNPO3 expression increases and shows nuclear and cytoplasmic localization, while decreasing in the middle stage with a localization mainly limited to the cytoplasm. In the late differentiation step, TNPO3 goes back to increase and localize particularly in the cytoplasm. In addition we verified the pattern of expression of some myomiRNAs (miRNA 1, miRNA 206, miRNA 133) specifically involved in myogenesis and atrophy, which expression increases during differentiation. In the end we analyzed the expression of some specific proteins involved in muscle atrophy (such as Murf-1 and p62), which remains the common feature of myofibres of LGMD1F patients.

68. Peterle E, Fanin M, Semplicini C, et al. Clinical phenotype, muscle MRI and muscle pathology of LGMD1F. J Neurol 2013;260:2033-41.

69. Cenacchi $G$, Peterle E, Fanin M, et al. Ultrastructural changes in LGMDIF. Neuropathology 2013;33:276-80.

70. Torella A, Fanin M, Mutarelli M, et al. Next-generation sequencing identifies transportin 3 as the causative gene for LGMDIF. PLoS One 2013;8:e63536.

71. Harel A, Forbes DJ. Importin Beta: Conducting a Much Larger Cellular Symphony. Mol Cell 2004;16:319-30.

72. Ferri P, Barbieri E, Burattini S, et al. Expression and subcellular localization of myogenic regulatory factors

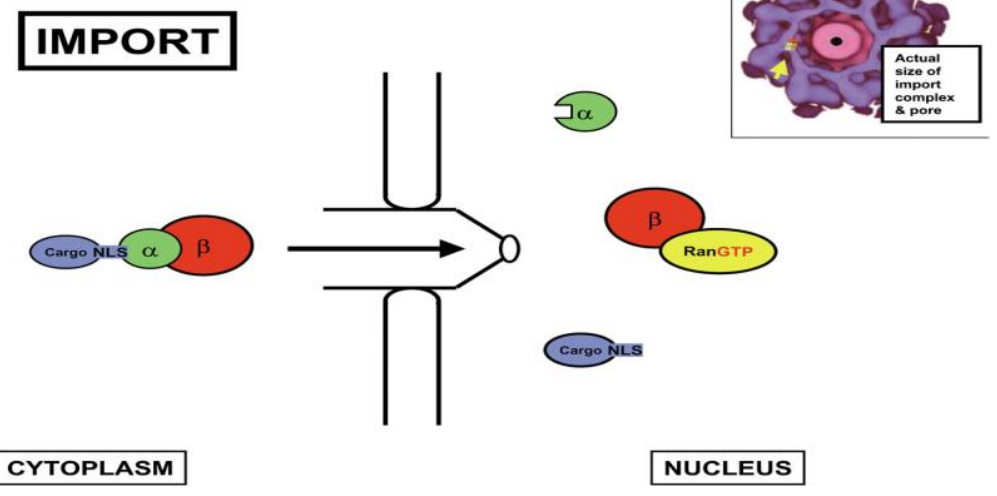

Fig 12. Nuclear import. The nuclear localization signal (NLS) on protein cargo is recognized by importin- $\alpha$, which in turn binds to importin $\beta$. This import complex translocates to the nucleus through the nuclear pore. ${ }^{4}$ 
during the differentiation of skeletal muscle C2C12 myoblasts. J Cell Biochem 2009;108:1302-17.

73. Corbu A, Scaramozza A, Badiali-DeGiorgi L, et al. Satellite cell characterization from aging human muscle. Neurol Res 2010;32:63-72.

$$
* * * * *
$$

\section{Determining significant gait parameters in total hip arthroplasty recovery using principal component analytic methods}

Chase D Latour (a), Kyle J Edmunds (b), Magnús K Gíslason (b), Throstur Hermannsson (b), Luca Esposito (c), Paolo Bifulco (d), Mario Cesarelli (d), Massimiliano Fraldi (c,e), Luca Cristofolini (f), Halldór Jr Jónsson ( $g, h)$, Paolo Gargiulo $(b, h)$

(a) Washington University in St. Louis, St. Louis, Missouri, USA, (b) Institute for Biomedical and Neural Engineering, Reykjavík University, Reykjavík, Iceland, (c) Department of Structures for Engineering and Architecture, University of Naples Federico II, Naples, Italy, (d) Department of Electrical Engineering and Information Technologies, University of Naples Federico II, Naples, Italy, (e) Interdisciplinary Research Centre for Biomaterials, University of Naples Federico II, Naples, Italy, (f) Department of Industrial Engineering, University of Bologna, Italy, $(\mathrm{g})$ Faculty of Medicine, University of Iceland, Reykjavík, Iceland, (h) Department of Science, Landspítali, Reykjavík, Iceland, (h) Orthopedic Clinic, University HospitalLandspítali, Reykjavík, Iceland

\section{Email: cdlatour@wustl.edu}

Key Words: Multimodal Analysis, Total Hip Arthroplasty, Electromyography, Bone Mineral Density

Total Hip Arthroplasty is becoming a common, successful orthopedic procedure worldwide; however, to date there has been little emphasis on understanding the patient-specific recovery process post-surgery. ${ }^{74-79}$ Thus, we aim to determine a multi-metric assembly as a first step toward creating a clinical tool to assess patient recovery. Here, at both pre- and one-year post-surgery time points, we measured 11 spatial temporal gait parameters, bone mineral density around the implant stem, tissue density of and electro-myographic signals from the rectus femoris, vastus lateralis, and vastus medialis muscles. We completed computer tomographic scans on 48 total hip arthroplasty patients (receiving either cemented or uncemented implants) undergoing unilateral primary surgery. ${ }^{75}$ To create the multi-metric assembly, we first determined which variables showed a significant difference between their pre- and postsurgery measurements for each patient using either Student t-tests or Wilcoxon signed rank tests, depending on variable distribution type. ${ }^{78}$ We then used principal component analytic methods, ${ }^{76,77}$ to determine which variables, out of those demonstrating significant differences, contributed redundant information to the dataset. ${ }^{77}$ Those variables were then removed from the original set of significant variables. For both analyses, we determined normalcy of the variables using ShapiroWilks tests and transformed those that were non-normal

Table 2. Results of Principal Component Analysis and Variable Selection Method. Components are displayed from lowest to highest proportion of variance explained because variables are associated, starting from the component with the smallest eigenvalue, to only those components with eigenvalues less than 0.70. Components with eigenvalues larger than this do not have a variable assigned to them for removal.

\begin{tabular}{|l|l|l|l|}
\hline Component & Eigenvalue & $\begin{array}{l}\text { Proportion of Variance Explained } \\
\text { by the Component }\end{array}$ & $\begin{array}{l}\text { Variable Associated with Component } \\
\text { Component Loading) }\end{array}$ \\
\hline 15 & $1.354 \times 10^{-36}$ & 0.000 & Stance (Healthy) $(0.689)$ \\
\hline 14 & $9.860 \times 10^{-34}$ & 0.000 & Stride Length $(0.776)$ \\
\hline 13 & $5.121 \times 10^{-4}$ & 0.000 & Proximal BMD $(0.693)$ \\
\hline 12 & $1.046 \times 10^{-2}$ & 0.001 & Single Support (Operated) (-0.590) \\
\hline 11 & $1.843 \times 10^{-2}$ & 0.001 & Double Support $(-0.472)$ \\
\hline 10 & $5.244 \times 10^{-2}$ & 0.004 & Velocity (-0.360) \\
\hline 9 & $9.004 \times 10^{-2}$ & 0.006 & RF Muscle Density (Operated) $(-0.442)$ \\
\hline 8 & $1.807 \times 10^{-1}$ & 0.012 & Step Length (Operated) $(-0.692)$ \\
\hline 7 & $3.260 \times 10^{-1}$ & 0.022 & Toe In/Out Angle (Operated) $(-0.460)$ \\
\hline 6 & $5.971 \times 10^{-1}$ & 0.040 & Toe In/Out Angle (Healthy) $(0.595)$ \\
\hline 5 & $7.281 \times 10^{-1}$ & 0.049 & No variable associated \\
\hline 4 & 1.027 & 0.068 & No variable associated \\
\hline 3 & 2.045 & 0.136 & No variable associated \\
\hline 2 & 2.913 & 0.194 & No variable associated \\
\hline 1 & 7.011 & 0.467 & No variable associated \\
\hline
\end{tabular}


before we included them in the principal component analysis. We found that 15 of the measured variables were sensitive to changes pre- versus post-surgery (Table $2)$. The variables which were most sensitive to postoperative changes were the gait measurements, the muscle densities of the rectus femoris and vastus medialis, both the proximal and distal bone mineral densities, and one electromyographic signal. To summarize, using the principal component analysis, we determined a subgroup of 5 variables which decreased redundancy in the dataset. Our findings indicate that developing a tool to assess patient recovery post-surgery is clinically feasible.

74. Vincent KR, Vincent HK, Lee LW, Weng J, Alfano AP. Outcomes after in-patient rehabilitation of primary and revision total hip arthroplasty. Arch Phys Med Rehabil 2006;87:1026.

75. Edmunds KJ, Gíslason MK, Arnadottir ID, et al. Quantitative computed tomography and image analysis for advanced muscle assessment. Eur J Transl Myol 2016 Jun 22;26(2):6015. doi: 10.4081/ejtm.2016.6015. eCollection 2016 Jun 13.

76. Eisler T, Svensson O, Tengström A, Elmstedt E. Patient expectation and satisfaction in revision total hip arthroplasty. J Arthroplasty 2002;17:457.

77. Jolliffe T. Discarding variables in a principal component analysis. I: Artificial data. J Royal Statistical Soc 1972 Series C (Applied Statistics);21:160.

78. King J, Jackson D. Variable selection in large environmental data sets using principal component analysis. Environmetrics 1999;10:67.

79. Magnússon B, Pétursson P, Edmunds K, et al. Improving planning and post-operative assessment for total hip arthroplasty. Euro J Transl Myol 2015;25:4913. doi:10.4081/ejtm.2015.4913.

$* * * * *$

Functional Electrical Stimulation: Training parameters optimized for age, resting options and denervation time

Christian Hofer (a), Helmut Kern(b), Stefan Löfler(b), Winfried Mayr (c)

(a). Ludwig Boltzmann Institute of Electrical

Stimulation and Physical Rehabilitation,

Wilhelminenspital Wien, Austria; (b). Physiko- und

Rheumatherapie, St. Poelten, Austria; (c). Center of

Medical Physics and Biomedical Engineering, Medical University of Vienna, Austria

E-mail: christian.hofer@wienkav.at

Key words: $\quad$ human denervated muscle, h-bFES, recovery, external-work contractility, muscle bulk.

The stimulation parameters applied for eliciting muscle contractions are depending on physiological conditions of the muscle. Of particular importance for electrical stimulation is whether the connection between the muscle and the nerve is preserved or the muscle is denervated due to Spinal Cord Injury or peripheral nerve lesion. In the latter cases the denervated muscle becomes unexcitable with commercial electrical stimulators and undergoes ultra structural disorganization within a few months, while severe atrophy with nuclear clumping and fibro-fatty degeneration appears later on within 3 and 6 years. ${ }^{80-82}$ This changes are essential for developing stimulation protocols since functional activation of denervated muscles requires electrical stimulation with long impulse duration in the range of $20-150$ (up to 300) ms. Moreover, contrary to innervated muscle where the nerve distributes the action potential in the denervated muscle an electrical field distribution capable of depolarizing the fibers in almost every part of the muscle has to be achieved. Therefore, to counteract the deterioration of the denervated muscle a therapy concept for home-based electrical stimulation was developed. To carry out the training a stimulator suited to deliver the necessary high-intensity and long duration impulses and new electrodes were designed. ${ }^{83,84}$ Specific clinical assessments to monitor the condition of the patient's muscles and guidelines for training were developed at the Wilhelminenspital Wien, Austria. ${ }^{83}$ The novel therapy concept (Figure 13), together with the newly designed devices, was evaluated in the RISE clinical study. After completing the 2-year home-based therapy program the

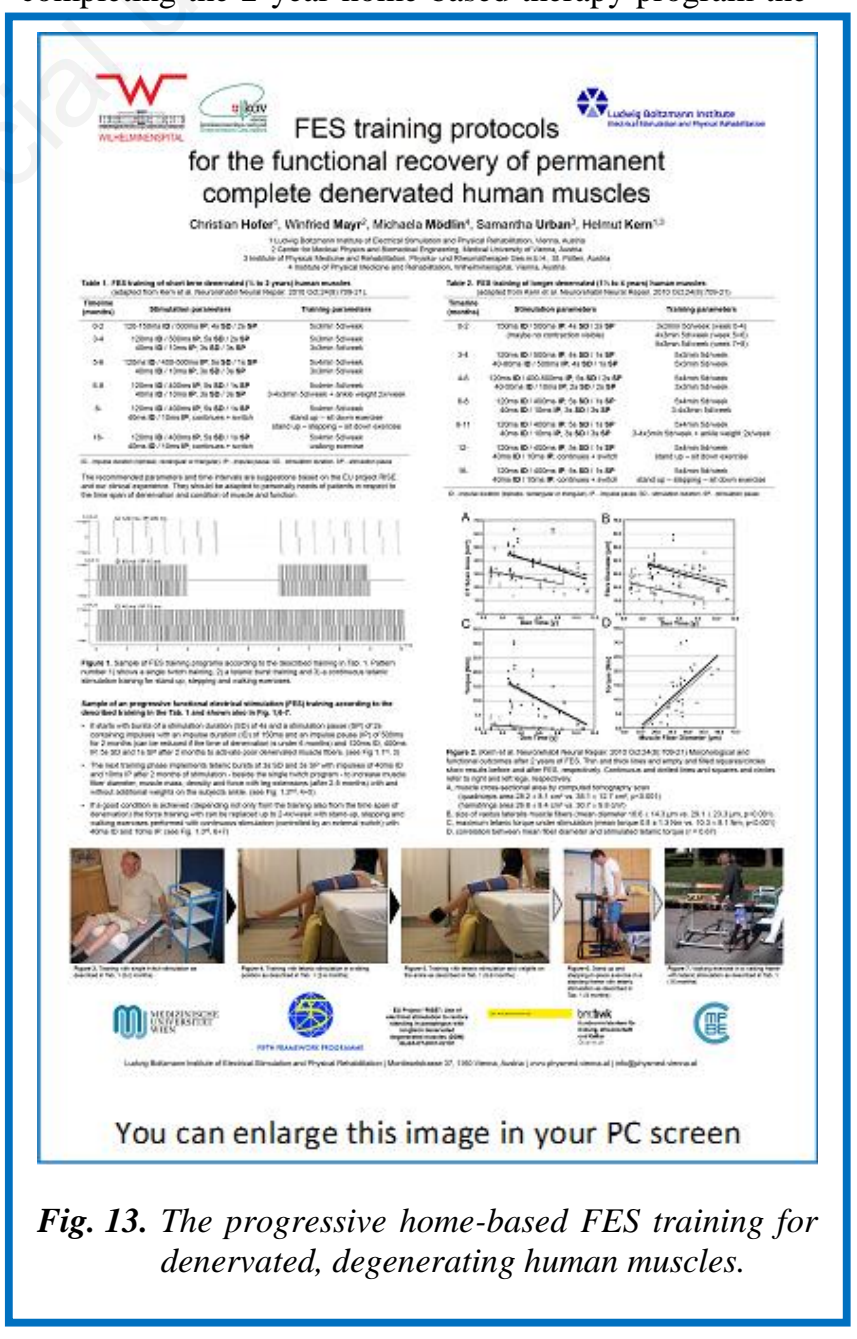


subjects showed a significant increase of muscle mass and of myofiber size, improvements of the ultrastructural organization and recovery of tetanic contractility with significant increase in developed muscle force output during electrical stimulation. ${ }^{84} \mathrm{EC}$ approved products (Stimulette den2x) and purpose constructed large safety electrodes are now commercially available (Schuhfried, Vienna, Austria. https://www.schuhfried.com/umbraco/Surface/Authenti cationSurface/Login?returnUrl=\%2Fportal ). ${ }^{85}$

80. G, Hofer Ch, Zampieri, et al. In complete SCI patients, long-term Functional Electrical Stimulation of permanent denervated muscles increases epidermis thickness. Neurol Res 2018, in press.

81. Carraro U, Boncompagni $S$, Gobbo V, et al. Persistent Muscle Fiber Regeneration in Long Term Denervation. Past, Present, Future. Eur J Transl Myol 2015 Mar 11;25(2):4832. doi: 10.4081/ejtm.2015.4832. eCollection 2015 Mar 11. Review.

82. Carraro U, Kern H. Severely Atrophic Human Muscle Fibers With Nuclear Misplacement Survive Many Years of Permanent Denervation. Eur J Transl Myol. 2016 Jun 13;26(2):5894. doi: 10.4081/ejtm.2016.5894. PMID: 27478559.

83. Hofer C, Mayr W, Stöhr H, et al. A stimulator for functional activation of denervated muscles. Artif Organs 2002;26:276-9.

84. Kern H, Hofer C, Mayr W, Carraro U. European Project RISE: Partners, protocols, demography. Eur J Transl Myol 2009;19:211-6.

$$
* * * * *
$$

\section{Cumulative references of Chapter II}

1. Aydemir TB, Troche C, Kim J, et al. Aging amplifies multiple phenotypic defects in mice with zinc transporter Zip14 (Slc39a14) deletion. Exp Gerontol 2016;85:88-94. doi: 10.1016/j.exger.2016.09.013. Epub 2016 Sep 16

2. Xu J, Hwang JC, Lees HA, et al. Long-term perturbation of muscle iron homeostasis following hindlimb suspension in old rats is associated with high levels of oxidative stress and impaired recovery from atrophy. Exp Gerontol 2012;47:100-8. doi 10.1016/j.exger.2011.10.011. Epub 2011 Nov 4.

3. Xu J, Marzetti E, Seo AY, et al. The emerging role of iron dyshomeostasis in the mitochondrial decay of aging. Mech Ageing Dev 2010;131:487-93. doi: 10.1016/j.mad. 2010.04.007. Epub 2010 Apr 29.

4. Seo $A Y, X u$ J, Servais $S$, et al. Mitochondrial iron accumulation with age and functional consequences. Aging Cell 2008;7:706-16.

5. Xu J, Knutson MD, Carter CS, Leeuwenburgh C. PLoS One. Iron accumulation with age, oxidative stress and functional decline. 2008;3(8):e2865. doi: 10.1371/ journal.pone.0002865.6. Milan G, Romanello V, Pescatore F, et al. Regulation of autophagy and the ubiquitin-proteasome system by the FoxO transcriptional network during muscle atrophy. Nat Commun 2015;6:6670.

7. Carnio S, LoVerso F, Baraibar MA, et al. Autophagy impairment in muscle induces neuromuscular junction degeneration and precocious aging. Cell Rep 2014;8:1509-21.
8. Lapierre LR, Kumsta C, Sandri M, et al. Transcriptional and epigenetic regulation of autophagy in aging. Autophagy 2015;11:867-80.

9. Hammond MD, Bauer KA, Sharp JT, Rocha RD. Respiratory muscle strength in congestive heart failure. Chest 1990;98:1091-4.

10. Howell S, Maarek JM, Fournier M, et al. Congestive heart failure: differential adaptation of the diaphragm and latissimus dorsi. J Appl Physiol 1995;79:389-97.

11. Sieck GC, Fournier M. Diaphragm motor unit recruitment during ventilatory and nonventilatory behaviors. J Appl Physiol (1985) 1989;66:2539-45.

12. Dempsey JA, Romer L, Rodman J, et al. Consequences of exercise-induced respiratory muscle work. Respir Physiol Neurobiol 2006;151:242-50.

13. Kelley RC, Ferreira LF. Diaphragm abnormalities in heart failure and aging: mechanisms and integration of cardiovascular and respiratory pathophysiology. Heart Fail Rev 2017;22:191-207.

14. Dalla Libera L, Ravara B, Gobbo V, et al. A transient antioxidant stress response accompanies the onset of disuse atrophy in human skeletal muscle. J Appl Physiol (1985) 2009;107:549-57. doi: 10.1152/ japplphysiol. 00280.2009. Epub 2009 May 28.

15. Kraemer WJ, Adams $K$, Cafarelli E, et al. American college of sports medicine position stand. Progression models in resistance training for healthy adults. Med Sci Sports Exerc 2002;34:364-80.

16. Moritani T, deVries HA. Neural factors versus hypertrophy in the time course of muscle strength gain. Am J Phys Med 1979;58:115-30.

17. Seynnes OR, de Boer M, Narici MV. Early skeletal muscle hypertrophy and architectural changes in response to high-intensity resistance training. J Appl Physiol (Bethesda, Md 1985) 2007;102:368-73.

18. Dankel SJ, Buckner SL, Jessee MB, et al. Correlations do not show cause and effect: Not even for changes in muscle size and strength. Sports Med 2018;48:1-6. doi: 10.1007/s40279-017-0774-3.

19. Hubal MJ, Gordish-Dressman H, Thompson PD, et al. Variability in muscle size and strength gain after unilateral resistance training. Med Sci Sports Exerc 2005;37: 964-72.

20. Ahtiainen JP, Walker S, Peltonen H. et al. Heterogeneity in resistance training-induced muscle strength and mass responses in men and women of different ages. Age (Dordr) 2016;38:10.

21. Bamman MM, Petrella JK, Kim JS, et al. Cluster analysis tests the importance of myogenic gene expression during myofiber hypertrophy in humans. J Appl Physiology (Bethesda, Md: 1985) 2007;102:2232-9.

22. Barbalho MSM, Gentil P, Izquierdo $M$, et al. There are no no-responders to low or high resistance training volumes among older women. Exp Gerontol 2017;99:1826.

23. Timmons JA. Variability in training-induced skeletal muscle adaptation. J Appl Physiol (1985) 2011;110:84653.

24. Paoli A. Resistance training: The multifaceted side of exercise. Am J Physiol Endocrinol Metabol 2012;302 E387.

25. Paoli A, Bianco A. Not all exercises are created equal. Am J Cardiol 2012;109:305. doi: 10.1016/j. amjcard.2011.10.011. 


\section{SpPMD: Giovanni Salviati Memorial, March 15-17}

Eur J Transl Myol 28 (1): 10-29, 2018

26. Bonaldo P, Sandri M. Cellular and molecular mechanisms of muscle atrophy. Disease Models \& Mechanisms 2013;6:25. doi: 10.1242/dmm.010389. Review

27. Lavorato $M$, Gupta PK, Hopkins PM, FranziniArmstrong C. Skeletal muscle microalterations in patients carrying malignant hyperthermia-related mutations of the e-c coupling machinery. Eur J Transl Myol $2016 \quad$ Sep 15;26:6105. doi: 10.4081/ejtm.2016.6105. eCollection 2016 Sep 15.

28. Missiaen L, Robberecht W, van Den Bosch $L$, et al. Abnormal intracellular calcium homeostasis and disease. Cell Calcium 2000;28:1.

29. Protasi F. Mitochondria association to calcium release units is controlled by age and muscle activity. Eur J Transl Myol 2015;25:257-62. doi: 10.4081/ejtm.2015.5604. eCollection 2015 Aug 24.

30. Totzeck A, Mummel P, Kastrup O, Hagenacker T. Clinical features of neuromuscular disorders in patients with N-type voltage-gated calcium channel antibodies. Eur J Transl Myol 2016;26:5962. doi: 10.4081/ejtm.2016.5962. eCollection 2016 Sep 15.

31. Wang X, Hockerman GH, Green 3rd HW, et al. Merg1a $K+$ channel induces skeletal muscle atrophy by activating the ubiquitin proteasome pathway. FASEB J 2006;20:1531.

32. Rutkowski DT, Kaufman RJ. That which does not kill me makes me stronger: adapting to chronic ER stress. Trends Biochem Sci 2007;32:469-76.

33. Szegezdi E, Fitzgerald U, Samali A. Caspase-12 and ERstress-mediated apoptosis: the story so far. Ann NY Acad Sci 2003;1010:186-94.

34. Moorwood C, Barton ER. Caspase-12 ablation preserves muscle function in the mdx mouse. Hum Mol Genet 2014;23:5325-41.

35. Sanes JR, Lichtman JW. Development of the vertebrate neuromuscular junction. Annu Rev Neurosci 1999;22:389-442.

36. Tintignac LA, Brenner HR, Ruegg MA. Mechanisms Regulating Neuromuscular Junction Development and Function and Causes of Muscle Wasting. Physiol Rev 2015;95:809-52.

37. Rigoni M, Montecucco C. Animal models for studying motor axon terminal paralysis and recovery. $J$ Neurochem 2017;142 Suppl 2:122-29. doi: 10.1111/jnc.13956. Epub 2017 Mar 21. Review.

38. Duregotti E, Negro S, Scorzeto M, et al. Mitochondrial alarmins released by degenerating motor axon terminals activate perisynaptic Schwann cells. Proc Natl Acad Sci U S A 2015;112:E497-E505.

39. Negro S, Lessi F, Duregotti E, et al. CXCL12alpha/SDF1 from perisynaptic Schwann cells promotes regeneration of injured motor axon terminals. EMBO Mol Med 2017;9:1000-1010. doi: 10.15252/emmm.201607257.

40. Forbes SC, Willcocks RJ, Triplett WT, Rooney WD, Lott DJ, Wang DJ, Pollaro J, Senesac CR, Daniels MJ, Finkel RS, Russman BS, Byrne BJ, Finanger EL, Tennekoon GI, Walter GA, Sweeney HL, Vandenborne K. PLoS One. 2014 Sep 9;9(9):e106435. doi: 10.1371/journal.pone. 0106435. eCollection 2014. Erratum in: PLoS One. 2014;9(10):e111822. et al. Magnetic resonance imaging and spectroscopy assessment of lower extremity skeletal muscles in boys with Duchenne muscular dystrophy: a multicenter cross sectional study. PLoS One 2014;9: e106435.

41. Wagner KR,McPherron AC, Winik N, Lee SJ. Loss of myostatin attenuates severity of muscular dystrophy in mdx mice. Ann Neurol 2002;52: 832-6.

42. Bish LT, Sleeper MM, Forbes SC, Morine KJ, Reynolds $C$, Singletary GE, Trafny D, Pham J, Bogan J, Kornegay $J N$, Vandenborne K, Walter GA, Sweeney HL. Long-term systemic myostatin inhibition via liver-targeted gene transfer in golden retriever muscular dystrophy. Hum Gene Ther 2011;22:1499-509.

43. Quattrocelli $M$, Barefield $D Y$, Warner $J L$, Vo $A H$, Hadhazy M, Earley JU, Demonbreun AR, McNally EM. Intermittent glucocorticoid steroid dosing enhances muscle repair without eliciting muscle atrophy. J Clin Invest 2017;127:2418-32.

44. Deenen JC, Arnts H, van der Maarel SM, Padberg GW, et al. Population-based incidence and prevalence of facioscapulohumeral dystrophy. Neurology 2014 Sep 16;83:1056-9

45. Lemmers RJ, Tawil R, Petek LM, et al. Digenic inheritance of an SMCHD1 mutation and an FSHDpermissive D4Z4 allele causes facioscapulohumeral muscular dystrophy type 2. Nat Genet 2012;44:1370-4.

46. Mason AG, Slieker RC, Balog J, et al. SMCHD1 regulates a limited set of gene clusters on autosomal chromosomes. Skelet Muscle. 2017;7:12.

47. Sacconi S, Lemmers RJ, Balog J, et al. The FSHD2 gene SMCHD1 is a modifier of disease severity in families affected by FSHD1. Am J Hum Genet 2013;93:744-51.

48. Teveroni E, Pellegrino M, Sacconi S, et al. Estrogens enhance myoblast differentiation in facioscapulohumeral muscular dystrophy by antagonizing DUX4 activity. J Clin Invest 2017;127:1531-45.

49. Fischer J, Lefèvre C, Morava E, et al. The gene encoding adipose triglyceride lipase (PNPLA2) is mutated in neutral lipid storage disease with myopathy. Nat Genet, 2007;39:28-30.

50. Tavian D, Missaglia S, Redaelli C, et al. Contribution of novel ATGL missense mutations to the clinical phenotype of NLSD-M: a strikingly low amount of lipase activity may preserve cardiac function. Hum Mol Genet, 2012;21:5318-28.

51. Campagna F, Nanni L, Quagliarini $F$, et al. Novel mutations in the adipose triglyceride lipasi gene causing neutral lipid storage disease with myopathy. Biochem Biophys Res Commun, 2008;377:843-6.

52. Missaglia S, Tasca E, Angelini C, et al. Novel missense mutations in PNPLA2 causing late onset and clinical heterogeneity of neutral lipid storage disease with myopathy in three siblings. Mol Genet Metab,2015;115:110-7.

53. Pennisi EM, Arca M, Bertini E, et al. Neutral Lipid Storage Diseases: clinical/ genetic features and natural history in a large cohort of Italian patients. Orphanet $J$ Rare Dis, 2017;12:90.

54. Angelini C, Fanin M. Calpainopathy. In: Adam MP, Ardinger HH, Pagon RA, Wallace SE, Bean LJH, Mefford HC, Stephens K, Amemiya A, Ledbetter $N$, editors. GeneReviews ${ }^{\circledR}$ Seattle (WA): University of Washington, Seattle; 1993-2017. 2005 [updated 2017].

55. Magri F, Nigro V, Angelini $C$, et al. The italian limb girdle muscular dystrophy registry: Relative frequency, 


\section{SpPMD: Giovanni Salviati Memorial, March 15-17}

Eur J Transl Myol 28 (1): 10-29, 2018

clinical features, and differential diagnosis. Muscle Nerve 2017;55:55-68. doi: 10.1002/mus.25192.

56. Bello L, Campadello P, Barp A, et al. Functional changes in Becker muscular dystrophy: implications for clinical trials in dystrophinopathies Sci Rep 2016;6:32439. doi: 10.1038/srep32439.

57. Barp A, Bello L, Politano L, et al. Genetic Modifiers of Duchenne Muscular Dystrophy and Dilated Cardiomyopathy. PLoS One 2015;10:e0141240.

58. Melacini $P$, Fanin $M$, Angelini A, et al. Cardiac transplantation in a Duchenne muscular dystrophy carrier. Neuromuscul Disord 1998;8:585-90.

59. Bonaldo P, Sandri M. Cellular and molecular mechanisms of muscle atrophy. Dis Model Mech 2013;6:25-39.

60. Powers SK, Morton AB, Ahn B, et al. Redox control of skeletal muscle atrophyforce and atrophy of hindlimb unloaded rat soleus by hampering neuronal nitric oxide synthase untethering from sarcolemma. J Physiol 2014; 592: 2637-2652.. Free Radic Biol Med 2016;98:208-17.

61. Suzuki N, Motohashi N, Uezumi A, et al. NO production results in suspension induced muscle atrophy through dislocation of neuronal NOS. J Clin Invest 2007;117:2468-76.

62. Vitadello M, Gherardini J, Gorza L. The stress protein/chaperone Grp94 counteracts muscle disuse atrophy by stabilizing subsarcolemmal neuronal nitric oxide synthase. Antioxid Redox Signal 2014;20:2479. 2496

63. Lawler JM, Kunst M, Hord JM, et al. EUK-134 ameliorates nNOSmu translocation and skeletal muscle fiber atrophy during short-term mechanical unloading. Am J Physiol Regul Integr Comp Physiol 2014;306:R470-R482.

64. Vitadello M, Germinario E, Ravara B, et al. Cellular and molecular mechanisms of muscle atrophy. Dis Model Mech 2013;6:25-39.

65. Toniolo L, Nagaraj N, Ciciliot S, et al . Single Muscle Fiber Proteomics Reveals Fiber-Type-Specific Features of Human Muscle Aging. Cell Rep 2017 Jun 13;19(11):2396-2409

66. Deshmukh AS, Murgia M, Nagaraj N, et al. Deep proteomics of mouse skeletal muscle enables quantitation of protein isoforms, metabolic pathways, and transcription factors. Mol Cell Proteomics 2015;14:84153.

67. Murgia M, Nagaraj N, Deshmukh AS, et al. Single muscle fiber proteomics reveals unexpected mitochondrial specialization. EMBO Rep 2015;16:387-95

68. Peterle E, Fanin M, Semplicini C, et al. Clinical phenotype, muscle MRI and muscle pathology of LGMD1F. J Neurol 2013;260:2033-41.

69. Cenacchi $G$, Peterle E, Fanin $M$, et al. Ultrastructural changes in LGMD1F. Neuropathology 2013;33:276-80.

70. Torella A, Fanin M, Mutarelli M, et al. Next-generation sequencing identifies transportin 3 as the causative gene for LGMD1F. PLoS One 2013;8:e63536.
71. Harel A, Forbes DJ. Importin Beta: Conducting a Much Larger Cellular Symphony. Mol Cell 2004;16:319-30.

72. Ferri P, Barbieri E, Burattini S, et al. Expression and subcellular localization of myogenic regulatory factors during the differentiation of skeletal muscle C2C12 myoblasts. J Cell Biochem 2009;108:1302-17.

73. Corbu A, Scaramozza A, Badiali-DeGiorgi L, et al. Satellite cell characterization from aging human muscle. Neurol Res 2010;32:63-72.

74. Vincent KR, Vincent HK, Lee LW, Weng J, Alfano AP. Outcomes after in-patient rehabilitation of primary and revision total hip arthroplasty. Arch Phys Med Rehabil 2006;87:1026.

75. Edmunds KJ, Gíslason MK, Arnadottir ID, et al. Quantitative computed tomography and image analysis for advanced muscle assessment. Eur J Transl Myol 2016 Jun 22;26(2):6015. doi: 10.4081/ejtm.2016.6015. eCollection 2016 Jun 13

76. Eisler T, Svensson O, Tengström A, Elmstedt E. Patient expectation and satisfaction in revision total hip arthroplasty. J Arthroplasty 2002;17:457.

77. Jolliffe T. Discarding variables in a principal component analysis. I: Artificial data. J Royal Statistical Soc 1972 Series C (Applied Statistics);21:160.

78. King J, Jackson D. Variable selection in large environmental data sets using principal component analysis. Environmetrics 1999;10:67.

79. Magnússon B, Pétursson P, Edmunds K, et al. Improving planning and post-operative assessment for total hip arthroplasty. Euro J Transl Myol 2015;25:4913. doi:10.4081/ejtm.2015.4913.80. G,

80. Hofer Ch, Zampieri, et al. In complete SCI patients, longterm Functional Electrical Stimulation of permanent denervated muscles increases epidermis thickness. Neurol Res 2018, in press.

81. Carraro U, Boncompagni S, Gobbo V, et al. Persistent Muscle Fiber Regeneration in Long Term Denervation. Past, Present, Future. Eur J Transl Myol 2015 Mar 11;25(2):4832. doi: 10.4081/ejtm.2015.4832. eCollection 2015 Mar 11. Review.

82. Carraro U, Kern H. Severely Atrophic Human Muscle Fibers With Nuclear Misplacement Survive Many Years of Permanent Denervation. Eur J Transl Myol. 2016 Jun 13;26(2):5894. doi: 10.4081/ejtm.2016.5894. PMID: 27478559 .

83. Hofer C, Mayr W, Stöhr H, Unger E, Kern H. A stimulator for functional activation of denervated muscles. Artif Organs 2002;26:276-9.

84. Kern H, Hofer C, Mayr W, Carraro U. European Project RISE: Partners, protocols, demography. Eur J Transl Myol 2009;19:211-6.

Received for publication: February 20, 2018

Accepted for publication: February 21, 2018 